\title{
A membrane bioreactor for biotransformations of hydrophobic molecules using organic solvent nanofiltration (OSN) membranes ${ }^{\text {is }}$
}

\author{
Rogelio Valadez-Blanco ${ }^{\text {a }}$, Frederico Castelo Ferreira ${ }^{\text {a, }}$, \\ Ruben Ferreira Jorge ${ }^{\mathrm{c}}$, Andrew Guy Livingston ${ }^{\mathrm{a}, *}$ \\ a Imperial College London, Department of Chemical Engineering and Chemical Technology, South Kensington Campus, London SW7 2AZ, UK \\ ${ }^{\mathrm{b}}$ REQUIMTE, Departamento de Química, Faculdade de Ciências e Tecnologia, Universidade Nova de Lisboa, 2829-516 Caparica, Portugal \\ ${ }^{\mathrm{c}}$ Escola Superior de Biotecnologia, R. Dr. António Bernardino de Almeida, 4200-072 Porto, Portugal
}

Keywords: Biphasic membrane bioreactor; Enantioselective biotransformations; Organic solvent nanofiltration membranes; Membrane extraction; Baker's yeast

\begin{abstract}
This work reports the application of organic solvent nanofiltration (OSN) membranes to a membrane bioreactor for biotransformations (MBB). An organic solvent phase was employed, allowing high substrate loadings and efficient product removal. The aqueous and organic phases were separated by an OSN membrane. The biotransformation of geraniol to $R$-citronellol by baker's yeast was used as the model reaction, and $n$-hexadecane and toluene as the organic solvents. The performance of the MBB was compared to that of a direct contact biphasic (DCB) bioreactor. The MBB system resulted in lower productivities than the DCB system due to mass transfer limitations. For the $n$-hexadecane system, the membrane was the main mass transfer resistance, whereas for the toluene system the contribution of the aqueous liquid film mass transfer resistance became predominant. Further investigations are needed to improve the substrate transfer rates. Despite this, the MBB system prevented aqueous breakthrough, and thus the formation of two-phase emulsions. Toluene toxicity to the biocatalyst was also minimized, although it caused a reduction in the reaction enantiospecificity. This work showed that OSN-MBB systems avoid the formation of emulsions, thus reducing downstream separation and allowing increased substrate loadings.
\end{abstract}

\footnotetext{
Abbreviations: CI, confidence interval; DCB, direct contact biphasic; e.e., enantiomeric excess; GC, gas chromatography; HPLC, high performance liquid chromatography; MBB, membrane bioreactor for biotransformations; MBB$\mathrm{HD}$, membrane bioreactor for biotransformations using $n$-hexadecane as the organic phase; MBB-Tol, membrane bioreactor for biotransformations using toluene as the organic phase; $\operatorname{NADP}(\mathrm{H})$, nicotinamide adenine dinucleotide phosphate (reduced); NMR, nuclear magnetic resonance; GLC-MS, gas liquid chromatography-mass spectrometry; OMTC, overall mass transfer coefficient; OSN, organic solvent nanofiltration; SEM, scanning electron microscopy

is Presented at Euromembrane 2006, 24-28 September 2006, Giardini Naxos, Italy; abstract published in Desalination 199 (2006) 429-431.

* Corresponding author at: Imperial College London, Department of Chemical Engineering, Room 218, ACE Building, South Kensington Campus, London SW7 2AZ, UK. Tel.: +44 20 75945582; fax: +44 2075945629.

E-mail addresses: a.livingston@imperial.ac.uk, a.livingston@ic.ac.uk (A.G. Livingston).

URL: http://www.imperial.ac.uk (A.G. Livingston).
}

\section{Introduction}

Biotransformations play an increasingly important role in organic synthesis for the production of fine chemicals, such as in the synthesis of chiral precursors [1]. However, an important number of substrates and products of biotransformations are poorly soluble in water, the medium in which most biocatalysts have optimal biological performance. Additionally, substrate and product above critical concentrations are known to inhibit biocatalytic activity [2,3]. Therefore, a significant obstacle to the application of biotransformations in industry is the limiting loading of substrate and product allowed in the reactor.

Direct contact biphasic (DCB) bioreactors overcome this limitation since favourable partitioning of substrates and products into the organic phase allows the use of high concentrations in this phase, while maintaining low concentrations in the aqueous phase. However, the intensive mixing of biomedium and organic phases can cause strong emulsions that make 
downstream separation a practical constraint. Moreover, the presence of the organic solvent can inhibit or even stop the biocatalyst activity [2,3].

To meet this challenge, membrane bioreactors for biotransformations (MBB) have been proposed [4-6] based on membrane extraction [7-10]. In these systems, a membrane separates the aqueous and organic phases. The aim is to avoid emulsion formation and phase toxicity of the organic solvent encountered in DCB systems, while enabling substrate and product transport. Two types of membranes have been used: microporous and non-porous.

Microporous membranes run into difficulties maintaining an aqueous-organic interface because species present in the biomedium can act as surfactants. These can cause a considerable reduction in the membrane breakthrough pressure, which leads to aqueous-organic phase breakthrough and mixing of the two phases $[4,5,11]$. A mechanism for this phenomenon was outlined by Shroen et al. [12] and Vaidya et al. [11]: they found that the decrease in the interfacial surface tension and breakthrough pressure is caused by surface active compounds, primarily proteins, that adsorb progressively onto the membrane pore walls, thus changing the wettability of the membrane. This protein adsorption ultimately leads to phase breakthrough and emulsion formation.

To prevent phase breakthrough during microporous $\mathrm{MBB}$ operation, the transmembrane pressure must be strictly controlled in the 100 mbar range, which is very difficult to achieve in actual membrane contactors [4,11,13]. Pronk et al. [5] reported the use of a Cuprophan hollow fiber membrane with an immobilized enzymatic system. The authors reported no phase breakthrough occurring up to 1 bar due to the ultrafiltration range of the membrane (MWCO $5000 \mathrm{Da}$ ). However, the membranes used were hydrophilic, and not compatible with organic solvents, nor were they suitable for extraction of hydrophobic molecules. Liese et al. [14] and Shin et al. [15] suggested an enzymatic MBB using two membrane stages: an ultrafiltration membrane was coupled to a bioreactor for retaining enzymes, and a second microfiltration hollow fiber membrane module was used as a two-phase extractor for product recovery. No phase breakthrough occurred at the extraction stage because the enzymes were not allowed to adsorb into the membrane pores. Chang et al. [16] reported the use of a similar two-stage bioreactorextractor system for an ethanol fermentation using suspended whole-cells.

Kang et al. [17] and Shukla et al. [18] implemented a whole-cell membrane bioreactor for alcohol and alcohol-acetone-butanol fermentations, respectively. No breakthrough occurred in their bioreactors. In these systems the biocatalysts were immobilised, which prevented cells and large biomolecules such as proteins - which are surface active from diffusing and adsorbing into the micropores: the suspended biomass concentration was very low $\left(0.15 \mathrm{~g} \mathrm{~L}^{-1}\right)$ compared with the entrapped biomass $\left(2 \mathrm{~g} \mathrm{~L}^{-1}\right)$. Molinari et al. [19] performed the suspended whole-cell biotransformation of isoamyl alcohol to isovaleraldehyde using a hollow-fiber membrane reactor. The membrane consisted of hydrophobic, microporous, polypropylene, Celgard fibres. After the authors had stabilised

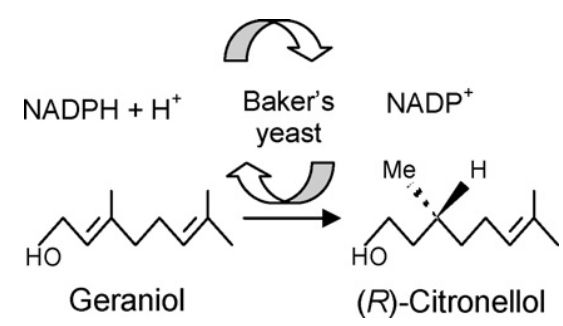

Fig. 1. Model biotransformation system: reduction of geraniol to $R$-citronellol by baker's yeast.

the membrane interface without biomass present, they reported phase breakthrough occurring when the microorganisms were suspended in the bioreactor.

Silicone rubber has been used as a non-porous membrane material because of its high permeability and selectivity to small hydrophobic molecules, and more importantly because it prevents aqueous breakthrough. The high permeability is due mainly to extensive swelling in the presence of organic solvents [20]. However, swelling causes expansion, leading to formation of wrinkles and cracks, and ultimately to bursting and problems handling the membrane. Therefore, a low degree of membrane swelling is a paramount consideration in the design and performance of organic solvent resistant membranes [21-23].

This work explores the use of a nanofiltration membrane, which is resistant to a wide range of organic solvents, to provide a stable biphasic interface without significantly sacrificing mass transfer of solutes. This approach is now possible with the development of organic solvent nanofiltration (OSN) membranes, which became commercially available in the 1990s [24-28]. In principle, these membranes conserve their integrity and performance in the presence of organic solvents $[21,29,30]$.

In contrast to microporous membranes, the very small pore size of the OSN membranes (in the nano-scale) should prevent the adsorption of surfactants into the membrane pores, thus preventing phase breakthrough. In addition, the characteristically low swelling of these membranes overcomes the problem of poor solvent resistance observed in silicone rubber membranes. Therefore, we assess the feasibility of using an OSN membrane as a selective separating layer between the aqueous and the organic phase, thus assisting biotransformations of hydrophobic molecules.

An integrally skinned asymmetric membrane, Starmem ${ }^{\mathrm{TM}}$ $122^{1}$, was selected on the basis of reactant and product molecular size. Either $n$-hexadecane or toluene were used as the organic solvents. The production of $R$-citronellol $\left(M_{\mathrm{w}} 156 \mathrm{~g} \mathrm{~mol}^{-1}\right)$ from geraniol $\left(M_{\mathrm{w}} 154 \mathrm{~g} \mathrm{~mol}^{-1}\right)$ by baker's yeast was selected as a model biotransformation system (Fig. 1). Gramatica et al. [31], using a dense suspension of baker's yeast resting cells, reported that the biotransformation yielded $25 \%$ of enantiomerically pure $R$-citronellol. In this system, $\operatorname{NADP}(\mathrm{H})$, the reduced form of the cofactor, is used to provide the reaction reduction

\footnotetext{
${ }^{1}$ Starmem $^{\mathrm{TM}}$ is a trademark of W.R. Grace and Co. These membranes are known to be stable in organic solvents such as alcohols, alkanes, aromatics some ethers and ketones (e.g. methyl-tert-butyl-ether, methyl-ethyl-ketone, methyliso-butyl-ketone), as well as in acetic acid, butyraldehyde and ethyl acetate.
} 
potential and is regenerated by the cells. Doig et al. [32] implemented this biocatalytic reaction in an MBB using a non-porous silicone-rubber membrane.

The mass transfer rates of product and substrate through the OSN membrane were measured to gain insight into the transport phenomena. Then, the effectiveness of the MBB-OSN system was explored by comparing its performance with that of a DCB bioreactor in terms of volumetric productivity, enantiomeric excess (e.e.) and product quality.

\section{Materials and methods}

\section{Chemicals and membrane}

Citronellol (95\%) and geraniol (99\%) were purchased from Acros Organics (Geel, Belgium). $n$-Hexadecane (99\%), $R$ - and $S$-citronellol (standards for e.e. analyses), glucose and fast dried baker's yeast type 2 (Saccharomyces cerevisiae) were purchased from Sigma-Aldrich (Steinhelm, Germany). $\mathrm{K}_{2} \mathrm{HPO}_{4}(>98 \%)$ and dichloromethane (99\%) were purchased from BDH-VWR (Poole, England). Toluene, $n$-hexane and isopropanol (HPLC grade) were purchased from Fisher Scientific Ltd. (Leicestershire, UK). KOH (97\%) was obtained from Rose Chemicals (London, UK). Starmem ${ }^{\mathrm{TM}} 122$ membranes (W.R. Grace \& Co.), polyimide asymmetric membranes with a nominal molecular weight cut off of $220 \mathrm{gL}^{-1}$, were kindly supplied by Membrane Extraction Technology Ltd. (UK).

\section{Analytical methods}

Two GC systems have been employed in the citronellol and geraniol concentration analyses: (a) a Unicam GC, equipped with a 19477-088 Supelco wax-10 column, $30 \mathrm{~m} \times 0.25 \mathrm{~mm} \times 0.25 \mu \mathrm{m}$ film thickness, and (b) an Agilent 6850 Series II Network Gas Chromatograph system (USA) with an Agilent HP-1 capillary column, $30 \mathrm{~m} \times 0.32 \mathrm{~mm}$ nominal diameter $\times 0.25 \mu \mathrm{m}$ film thickness, $100 \%$ dimethylpolysiloxane phase, No. 19091Z-413E (AnaChem, UK). Both systems were equipped with a flame ionisation detector. The Agilent GC was used for the mass transfer tests, whereas the biotransformation samples were analysed with the Unicam GC, where citronellol and geraniol needed to be resolved. The coefficient of variation of five repeated measurements of citronellol in dichloromethane with the Agilent GC was 3.5\%, and that for the Unicam GC measurements was $0.8 \%$ using five repeated measurements of citronellol in $n$-hexadecane samples $\left(2000 \mathrm{mg} \mathrm{L}^{-1}\right)$. External standards were prepared and injected for all the sample runs.

For the quantification of citronellol and geraniol in the organic phase of the MBB ( $n$-hexadecane or toluene), $1 \mu \mathrm{L}$ of the organic phase was injected directly into the GC. In the case of the DCB biotransformations the emulsified samples $(1.2 \mathrm{~mL})$ were first centrifuged in an MSE Micro Centaur centrifuge (MSE, UK) at $13,000 \mathrm{rpm}$ for $5 \mathrm{~min}$. For analyses of citronellol and geraniol in the aqueous phase, $8 \mathrm{~mL}$ of samples of this phase were vortexed (Heidolph Reax Top tube vortex, Model 541, Germany) for $30 \mathrm{~s}$ together with $2 \mathrm{~mL}$ of dichloromethane. Then $1 \mu \mathrm{L}$ of the organic phase was analysed by GC as described above.
The e.e. of the bioreactor final products was determined by HPLC using a Daicel chiral column, Chiracel OJ-H $(250 \mathrm{~mm} \times 4.6 \mathrm{~mm}$ i.d.), purchased from Chiral Technologies Europe, France. A Unicam 200 HPLC pump (Unicam, UK) was fitted to an autosampler and to a 2550 Varian UV variable detector (Varian Instruments, Japan) set to a wavelength of $215 \mathrm{~nm}$. The mobile phase, 97.5:2.5 $n$-hexane/isopropanol, was pumped at a $0.5 \mathrm{~mL} \mathrm{~min}^{-1}$ flow rate at room temperature. Prior to HPLC analysis, samples in $n$-hexadecane were diluted 10 times with the mobile phase. Toluene samples $(2 \mathrm{~mL})$ were evaporated for 1 day in a water bath at $50^{\circ} \mathrm{C}$; then $5 \mathrm{~mL}$ of the mobile phase solution were added to solubilise the residue. Three samples were run for each of the e.e. determinations. The coefficients of variation were below $1 \%$ for the $n$-hexadecane samples, and $6.7 \%$ for the toluene analyses.

\section{Shake-flasks biotransformations}

The initial shake flask and bioreactor conditions used in this work were based on the optimised bioreactor conditions obtained by Doig et al. [33]. The aqueous phase comprised $40 \mathrm{mM}$ of $\mathrm{K}_{2} \mathrm{HPO}_{4}(\mathrm{pH} 9), 20 \mathrm{gL}^{-1}$ glucose and $15 \mathrm{~g} \mathrm{~L}^{-1}$ biomass (baker's yeast). In all the shake flask experiments, $200 \mathrm{~mL}$ of biomedium and $20 \mathrm{~mL}$ of organic solvent were used. The shake flasks were incubated at $37^{\circ} \mathrm{C}$ and $200 \mathrm{rpm}$ shaking speed in a Gallenkamp orbital incubator.

A series of four biphasic shake flasks was prepared to test the effect of toluene on the biocatalytic performance. The first test was used as a blank, in which no toluene was added to the $n$ hexadecane organic phase $(0 \mathrm{wt} \%)$. In the second and third tests, toluene was dissolved in the $n$-hexadecane phase at concentrations of 20 and $140 \mathrm{~g} \mathrm{~L}^{-1}$ (3 and $18 \mathrm{wt} \%$ ), respectively. Finally, in the fourth test, the $20 \mathrm{~mL} n$-hexadecane phase was replaced by a $20 \mathrm{~mL}$ toluene phase $(100 \mathrm{wt} \%)$. The geraniol concentration was $20 \mathrm{~g} \mathrm{~L}^{-1}$ in $n$-hexadecane for the first three shake flasks and $40 \mathrm{~g} \mathrm{~L}^{-1}$ in toluene for the last test to compensate for the higher partition of geraniol into toluene compared to that into $n$-hexadecane.

\section{DCB bioreactor biotransformations}

A New Brunswick Bioflo I (New Brunswick Scientific Ltd., UK) $2 \mathrm{~L}$ continuously stirred bioreactor was fitted with a Toledo $\mathrm{O}_{2}$ probe, a thermocouple and a VWR glass $\mathrm{pH}$ probe. Air at a flow rate of $0.5 \mathrm{~L} \mathrm{~min}^{-1}$ was bubbled into the bioreactor. The $\mathrm{pH}$ was controlled at 9.5 by addition of $4 \mathrm{M}$ $\mathrm{KOH}$. No acid addition was required to control the $\mathrm{pH}$. The reactor was maintained at $37^{\circ} \mathrm{C}$ using a heating jacket. Dissolved oxygen concentration, $\mathrm{pH}$ and temperature were read periodically. Initial volumes of $1500 \mathrm{~mL}$ of aqueous phase and $150 \mathrm{~mL}$ of organic phase were used. The aqueous phase was prepared by dissolving $10.5 \mathrm{~g}\left(7 \mathrm{~g} \mathrm{~L}^{-1}\right)$ of $\mathrm{K}_{2} \mathrm{HPO}_{4}, 30 \mathrm{~g}$

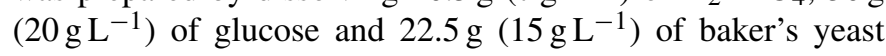
into $1500 \mathrm{~mL}$ of RO deionised water. Finally, a $150 \mathrm{~mL}$ organic phase was added; this consisted of $n$-hexadecane or toluene with a geraniol concentration of $20 \mathrm{~g} \mathrm{~L}^{-1}$ or $60 \mathrm{~g} \mathrm{~L}^{-1}$, respectively. 
DCB mixtures were prepared using both $n$-hexadecane and toluene as the organic phases. After stirring, the mixtures were left to settle for $1 \mathrm{~h}$ and centrifuged at $8500 \times g$ for $10 \mathrm{~min}$ in a Biofuge centrifuge (Heraeus Instruments, Germany). Finally, the organic phase was pipetted out from the centrifuge tubes and the organic volumes were measured before and after the recovery.

\section{Measurement of organic/aqueous partition coefficients}

Citronellol and geraniol were completely dissolved in a known volume of distilled water at initial concentrations slightly below their water solubility. A known volume of organic solvent was then added and the mixture was vortexed for $30 \mathrm{~s}$. After a $24 \mathrm{~h}$ settling period at room temperature, the aqueous and organic phases were separated and solute concentrations were determined by GC as described above. All partition coefficients obtained in this work are the average of three independent measurements. The coefficients of variation for the geraniol and citronellol partition coefficients were calculated as 2 and $10 \%$, respectively, and the mass balance error for the experiments was 3.6 and $1.5 \%$, respectively.

\section{Mass trnsfer experiments and MBB}

The apparatus used in the mass transfer and MBB experiments is illustrated in Fig. 2 [34]. The membrane, with an effective area of $0.015 \mathrm{~m}^{2}$, was placed in the middle of two stainless-steel half-cells with the active layer facing the aqueous phase. The membrane gaskets and tubing connections were made of PTFE. The average volumetric flow rates were 94 and $14 \mathrm{~L} \mathrm{~h}^{-1}$ for the aqueous and organic sides, respectively, except when otherwise stated. The membrane cell was adapted for mass transfer and MBB "reduced volume" experiments by modifying one of the half-cells: its interior height was decreased from 5 to $2.5 \mathrm{~mm}$, and its width and length were maintained.

The OSN membrane was preconditioned by circulating toluene overnight across both sides of the membrane in order to remove the preservative oil from inside the membrane and to fill the porous side of the membrane with the organic solvent. Toluene was then purged from both sides of the membrane; the active side of the membrane was flushed with water until no drops of organic solvents were observed, whereas the other side was flushed with several volumes of fresh organic solvent ( $n$-hexadecane or toluene) to wash out the toluene used for preconditioning. Higher pressure $(0.4 \mathrm{bar})$ was applied on the active side of the membrane, facing the aqueous solution, whereas 0.05 bar was applied to the organic side of the membrane.

For mass transfer experiments a solution of $200 \mathrm{mg} \mathrm{L}^{-1}$ of citronellol or geraniol in distilled water was used as the feed aqueous solution, and $n$-hexadecane or toluene was the organic extracting phase. After circulation of the solutions through the membrane cell for $15 \mathrm{~min}$, samples of the organic and aqueous reservoirs were taken at different time intervals and analysed

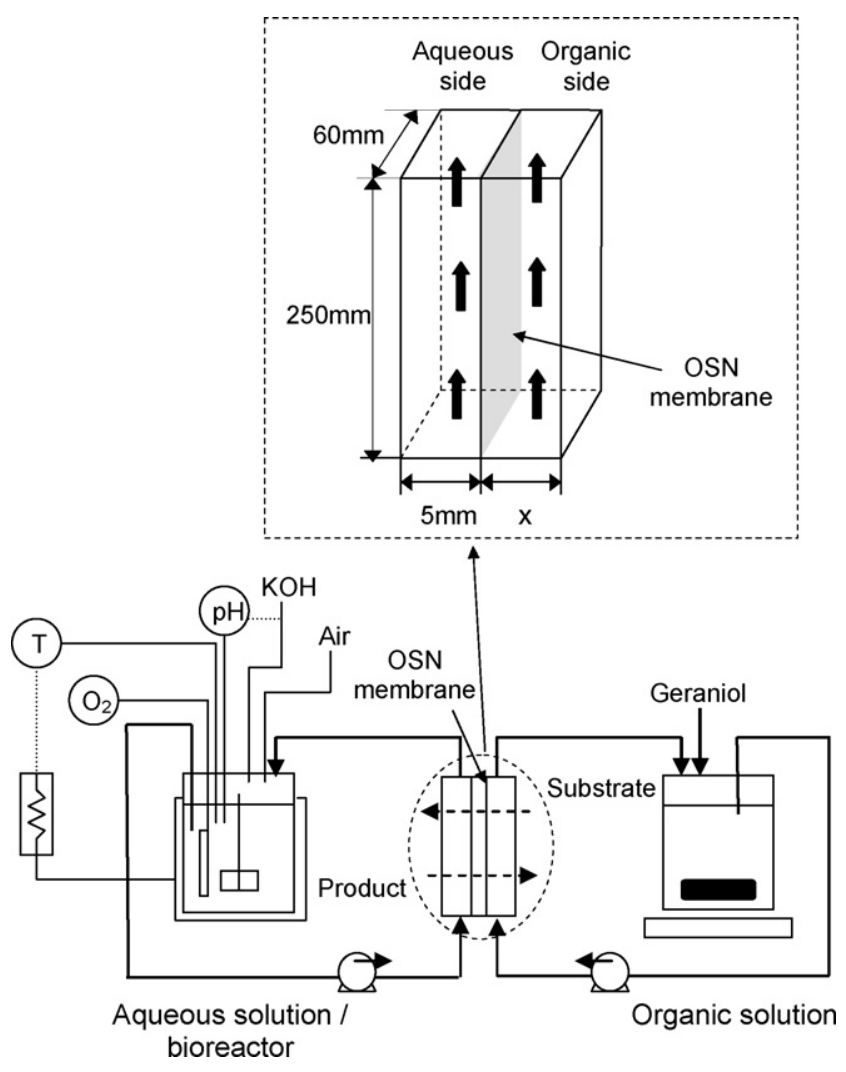

Fig. 2. Schematic of aqueous/organic membrane cell used for: (1) mass transfer experiments and (2) membrane bioreactor for biotransformations (MBB) using organic solvent nanofiltration (OSN) membranes.

by GC. Two to three runs were carried out for each test, and coefficients of variation of 4.4 and $10 \%$ were estimated for the measurements of the overall mass transfer coefficients (OMTC) of geraniol and citronellol, respectively, using $n$-hexadecane. Mass balances are also reported in Section 4. Additionally, a membrane cell with "reduced volume" was used for measuring the mass transfer at two different sets of flow rates: High (aqueous: $95 \mathrm{~L} \mathrm{~h}^{-1}$, organic: $18 \mathrm{~L} \mathrm{~h}^{-1}$ ) and Low (aqueous: $50 \mathrm{~L} \mathrm{~h}^{-1}$, organic: $9 \mathrm{~L} \mathrm{~h}^{-1}$ ).

The same bioreactor conditions (aqueous phase composition, air, temperature and $\mathrm{pH}$ ) and initial geraniol concentrations in the organic phase were employed for DCB and MBB experiments. In the MBB system, the aqueous phase containing $7 \mathrm{~g} \mathrm{~L}^{-1}$ of $\mathrm{K}_{2} \mathrm{PO}_{4}$ (pH 9), $20 \mathrm{~g} \mathrm{~L}^{-1}$ of glucose and $0.3 \mathrm{~g} \mathrm{~L}^{-1}$ of geraniol, was circulated through the membrane cell followed by the organic flow on the other side of the membrane. The MBB was left running overnight for equilibration of the substrate concentration between phases. Then, baker's yeast was added to the bioreactor and air was admitted into the system. Finally, periodic sampling of the organic and aqueous vessels was carried out, as well as readings of the bioreactor conditions $\left(\mathrm{O}_{2}\right.$, temperature and $\mathrm{pH}$ ). All MBB experiments were run for at least 5 days $(120 \mathrm{~h})$. In most of the MBB experiments the volumes of the aqueous and organic phases were 2000 and $200 \mathrm{~mL}$, respectively. Two different organic solvents were employed: $n$-hexadecane and toluene. The reduced volume MBB used 600 and $60 \mathrm{~mL}$ of aqueous and organic liquids, respectively. 


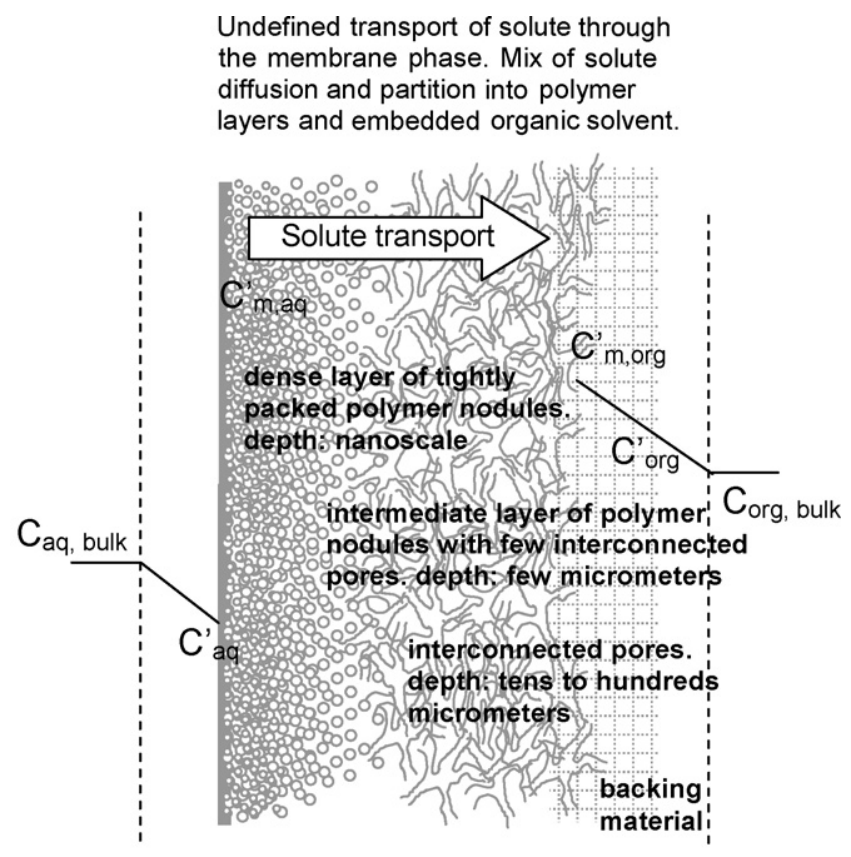

Aqueous liquid film

\section{OSN} Membrane

Organic liquid film

$$
\frac{1}{K_{a q}}=\frac{1}{k_{a q}}+\frac{1}{m_{m / a q}} \frac{1}{k_{m}}+\frac{1}{m_{\text {org } / a q}} \frac{1}{k_{\text {org }}}
$$

Fig. 3. Schematic of mass transport model of solutes through flat-sheet, hydrophobic, asymmetric, polyimide, OSN membranes separating an organic and an aqueous phase (based on SEM pictures and comments by See-Toh et al. [35]).

\section{Mathematical analysis}

Mass transfer resistances in an OSN membrane biphasic system

Fig. 3 shows a schematic of the transport model for a solute transferred from the aqueous to the organic phase through an OSN asymmetric membrane based on SEM pictures and comments by See-Toh et al. [35].

To date, the specific mass transfer mechanism inside the membrane is not known. For the mass transfer analysis in the OSN membrane biphasic system, we used a solution diffusion model considering the OSN membrane as non-porous. Therefore, the possible existence of a direct liquid-liquid interface at the porous mouth of the non-wetting phase is not taken into account. Instead, this work regards the membrane as an additional distinct phase (similar to a non-porous dense membrane) comprising both the membrane material and the absorbed wetting liquid. Polyimide membranes are hydrophobic so the organic solvent was the wetting liquid.

Using the overall mass transfer coefficient (OMTC) definition based on the aqueous phase (Eq. (1)):

$$
N=-V_{\text {aq }} \frac{\mathrm{d} C_{\text {aq }}}{\mathrm{d} t}=K_{\text {aq }}\left(C_{\text {aq }}-\frac{C_{\text {org }}}{m_{\text {org } / \mathrm{aq}}}\right)
$$

where $m_{\text {org/aq }}$ is the organic/aqueous partition coefficient at equilibrium:

$m_{\mathrm{org} / \mathrm{aq}}=\frac{C_{\mathrm{org}}^{*}}{C_{\mathrm{aq}}^{*}}$

we can obtain the following resistances-in-series mass transfer model for the mass transfer of solute from the aqueous bulk to the organic phase bulk through the membrane:

$$
\frac{1}{K_{\mathrm{aq}}}=\frac{1}{k_{\mathrm{aq}}}+\frac{1}{m_{\mathrm{m} / \mathrm{aq}}}\left(\frac{1}{k_{\mathrm{m}}}\right)+\frac{1}{m_{\mathrm{org} / \mathrm{aq}}}\left(\frac{1}{k_{\mathrm{org}}}\right)
$$

where $m_{\mathrm{m} / \mathrm{aq}}$ is the membrane/aqueous solute partition coefficient at equilibrium:

$m_{\mathrm{m} / \mathrm{aq}}=\frac{C_{\mathrm{m}}^{*}}{C_{\mathrm{aq}}^{*}}$

The following mechanism describes the transport of a solute from the bulk aqueous phase to the bulk organic phase (Fig. 3):

(1) Transfer from the aqueous solution bulk to the aqueous/membrane interface through the aqueous liquid film.

(2) Partition into the membrane.

(3) Diffusion across the membrane.

(4) Partition from the membrane into the organic liquid.

(5) Transfer from the membrane/organic-liquid interface to the bulk of the organic liquid through the organic-liquid film.

\section{Calculation of the overall mass transfer coefficient (OMTC), kaq}

To compute the OMTC we perform a solute mass balance considering transfer of solute from the aqueous to the organic phase:

$C_{\text {org }}=\frac{V_{\text {aq }}}{V_{\text {org }}}\left(C_{\text {aq }, 0}-C_{\text {aq }}\right)$

Fig. 4 shows experimental data on the changes of organic and aqueous concentrations for the mass transfer of a hydrophobic

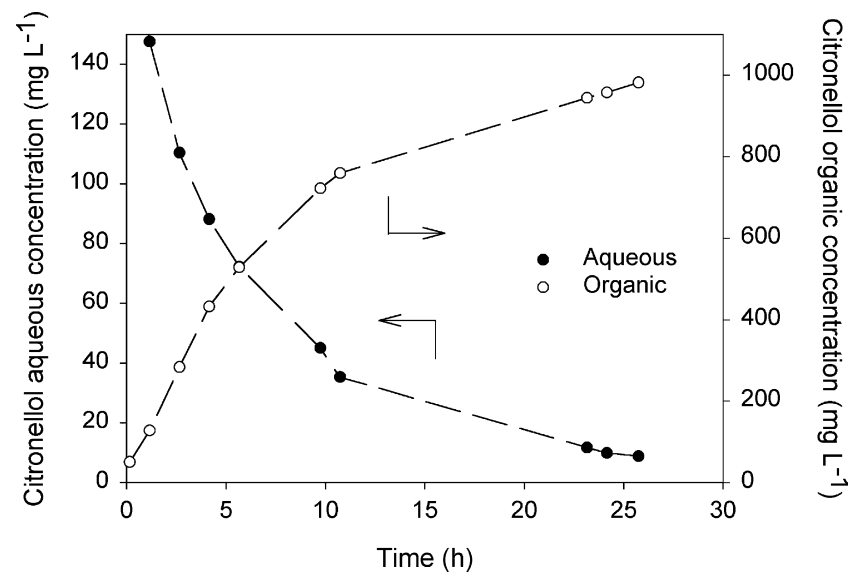

Fig. 4. Example of the citronellol concentration profiles in the aqueous and organic reservoirs (toluene) for the determination of the overall mass transfer coefficient (OMTC) through a Starmem ${ }^{\mathrm{TM}} 122$ membrane. 


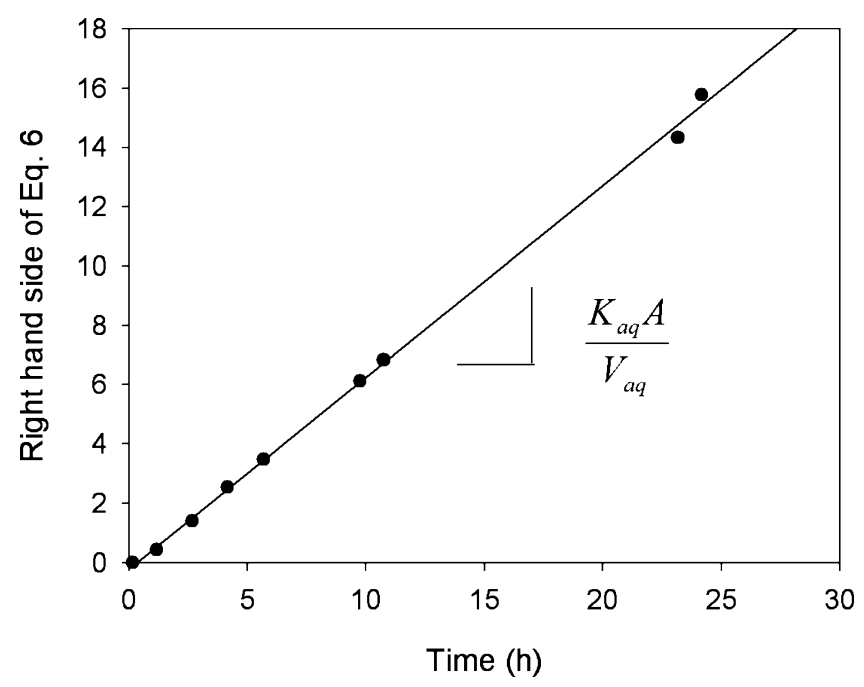

Fig. 5. Example of a plot of the right hand side of Eq. (6) against time for the calculation of the overall mass transfer coefficient (OMTC) of citronellol from an aqueous phase to toluene through a Starmem ${ }^{\mathrm{TM}} 122$ membrane.

solute, citronellol in this case, from the aqueous to the organic side.

All the calculations of the OMTC in this work are based on the aqueous concentrations as defined in Eq. (1). Substituting Eq. (5) in Eq. (1) and integrating, we obtain:

$$
\left(\frac{K_{\mathrm{aq}} A}{V_{\mathrm{aq}}}\right) t=\frac{1}{1+\alpha} \ln \left(\frac{C_{\mathrm{aq}, 0}}{(1+\alpha) C_{\mathrm{aq}}-\alpha C_{\mathrm{aq}, 0}}\right)
$$

where $\alpha=V_{\text {aq }} /\left(m_{\text {org/aq }} V_{\text {org }}\right)$.

For estimating the OMTC, the right hand side of Eq. (6) is plotted against time. This plot yields a linear curve with the slope $\left(K_{\mathrm{aq}} A / V_{\mathrm{aq}}\right)$ containing the OMTC. An example based on the experimental data from Fig. 4 is shown in Fig. 5.

\section{Estimation of individual mass transfer coefficients}

For estimating the individual liquid-film coefficients, $k_{\mathrm{aq}}$ and $k_{\text {org }}$, the Leveque exact solution [36] of the Navier-Stokes and convective mass transfer equations for circular pipes (Eq. (7)) gives a coefficient $a=1.62$ (Eq. (7a)). Three different correlations were used in this work: (1) Leveque solution for rectangular ducts, Eq. (7b) [37]. (2) An empirical correlation obtained from mass transfer data on rectangular ducts (Eq. (7c)) [37].

$S h=a\left(\frac{\operatorname{ReSc} d_{\mathrm{e}}}{L}\right)^{1 / 3}$

where

$$
\begin{aligned}
& a=1.62 \\
& a=1.85 \\
& a=2.33
\end{aligned}
$$

(3) An additional exact correlation for fully developed flow [38], Eq. (8):

$S h=R e^{1 / 3} S c^{1 / 3}\left(\frac{d_{\mathrm{e}}}{L}\right)^{0.43}$

where $S h=k_{\text {liq }} d_{\mathrm{e}} / D_{\mathrm{AB}}, R e=\rho v d_{\mathrm{e}} / \mu, S c=\mu / \rho D_{\mathrm{AB}}$.

The diffusivities, $D_{\mathrm{AB}}$, for the solutes (A) in the different solvents (B) were estimated using the Wilke-Chang correlation [39]:

$D_{\mathrm{AB}}=\frac{7.4 \times 10^{-8}\left(\phi_{\mathrm{B}} M_{\mathrm{B}}\right)^{1 / 2} T}{\mu_{\mathrm{B}} V_{\mathrm{A}}^{0.6}}$

An association factor, $\phi_{\mathrm{B}}$, of 2.26 was used for water and 1 for the organic solvents [40].

\subsection{Biotransformation performance parameters}

For characterising the performance of the biotransformations, the following concepts were used in this work:

Product yield, $Y=\frac{P}{S_{0}}$

Substrate consumption, $\mathrm{SC}=\frac{S_{0}-S}{S_{0}}$

Volumetric productivity, $\quad \mathrm{VP}=\frac{P}{V_{\mathrm{aq}} \times t}$

Specific activity, $\mathrm{SA}=\frac{P}{\text { biomass } \times t}$

$R$-Citronellol enantiomeric excess,

e.e. $(\%)=\left(\frac{R-S}{R+S}\right) \times 100$

\section{Results and discussion}

\section{Preliminary biotransformation testsn}

Initially the biotransformation of geraniol to citronellol by baker's yeast was tested in DCB shake-flasks. $n$-Hexadecane has been used here and in previous works due to its low toxicity to the biocatalyst $[33,41,42]$. The $\log P$ of a solvent provides an indication of the toxicity of the solvent to biocatalysts. In general, solvents with $\log P \geq 4$, i.e., very hydrophobic, do not affect biocatalyst activity since they do not distort the essential water shell of the cells [43]. $n$-Hexadecane possesses a very pronounced hydrophobic nature, given by its $\log P$ of 8.8 , which makes it compatible with most biocatalysts. However, it is not a suitable solvent for industrial applications because its high viscosity and boiling point make difficult to handle it and to recover the reaction final products.

Toluene is a more widely used solvent in the chemical industry. The $m_{\text {org/aq }}$ in toluene for the model substrate and product 
Table 1

Organic/aqueous partition coefficients, $m_{\mathrm{org} / \mathrm{aq}}$, for the model substrate and product in different organic solvents and solvent $\log P$

\begin{tabular}{|c|c|c|c|}
\hline & Geraniol & Citronellol & $\log P$ \\
\hline$n$-Hexadecane $\mathrm{a}^{\mathrm{a}}$ & 43 & 105 & 8.8 \\
\hline$n$-Heptane & 38 & 114 & 4.4 \\
\hline$n$-Hexane & 38 & 119 & 3.5 \\
\hline Toluene & 318 & 383 & 2.4 \\
\hline
\end{tabular}

a Doig et al. [10].

are about 7 and 4 times greater, respectively, than those in $n$ hexadecane as shown in Table 1. Alternative alkanes, such as $n$-hexane and $n$-heptane, have similar partitions to $n$-hexadecane (Table 1). Therefore, in addition to $n$-hexadecane we suggested the application of toluene as an alternative organic solvent for our MBB system. However, the $\log P$ of toluene (2.4) indicates that this solvent may be toxic to the biocatalyst. To evaluate this, a series of DCB shake-flask tests were carried out for 1 day, in which the effect of toluene was assessed using different organic/aqueous preparations.

When only $n$-hexadecane was used as the organic phase (Test 1, Fig. 6), the citronellol yield and volumetric productivity were slightly lower, with $95 \%$ confidence interval (CI), than when $40 \mathrm{~g} \mathrm{~L}^{-1}$ of toluene was added to an $n$-hexadecane organic phase (Test 2). On the other hand, in Test 3 , with $140 \mathrm{~g} \mathrm{~L}^{-1}$ of toluene in the $n$-hexadecane phase, the citronellol yield was significantly lower (with 95\% CI) than Test 1 and 2. However, the results of Test 3 are inconclusive since the $95 \%$ confidence interval for the volumetric productivity overlapped with that of Test 1 (Fig. 6). Finally, major inhibition of the biocatalyst activity occurred when a toluene organic phase was used (Test 4$)$. The solvent may have solubilised and destroyed the cellular membrane thus stopping the biotransformation. Chakraborty et al.

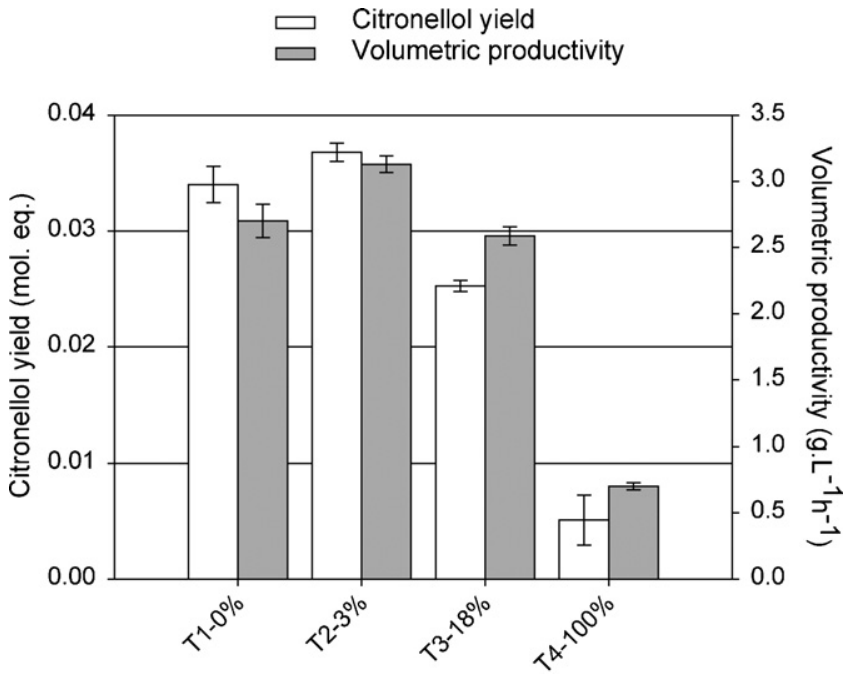

Toluene in $\mathrm{n}$-hexadecane phase (wt\%)

Fig. 6. Effect of toluene on the baker's yeast biocatalytic activity ( $24 \mathrm{~h}$ ) for the production of citronellol from geraniol in DCB shake flasks using different toluene concentrations in hexadecane-Test 1 (T1): $n$-hexadecane only ( $0 \mathrm{wt} \%)$; Test 2 (T2): $20 \mathrm{~g} \mathrm{~L}^{-1}$ of toluene in $n$-hexadecane (3 wt\%); Test 3 (T3): $140 \mathrm{~g} \mathrm{~L}^{-1}$ of toluene in $n$-hexadecane (18 wt \%); Test 4 (T4): toluene only (100 wt $\%$ ). (a)

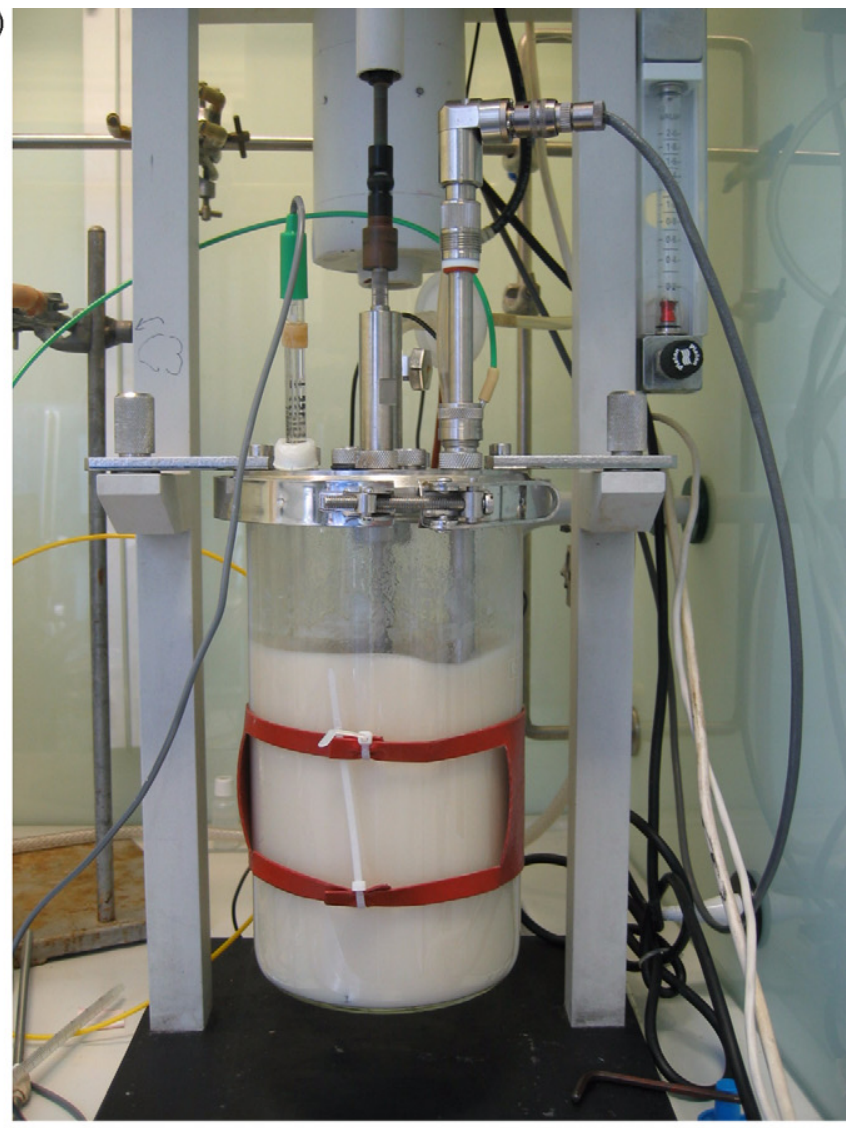

(b)

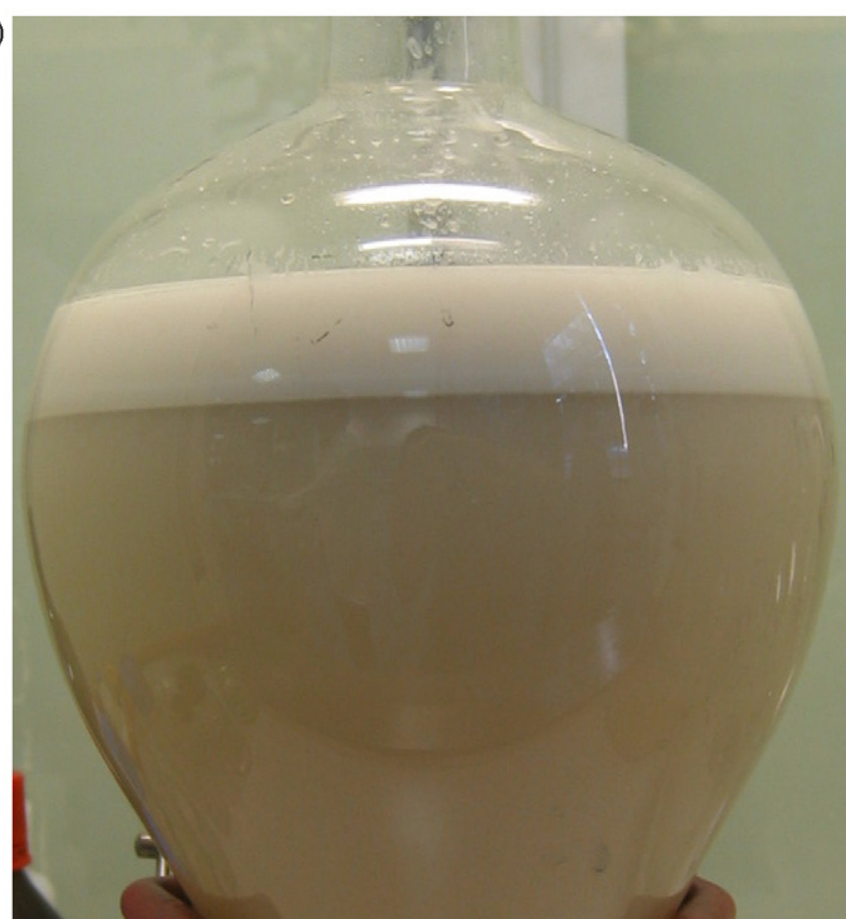

Fig. 7. (a) Picture of the DCB bioreactor for the biotransformation of geraniol to citronellol by baker's yeast using toluene as the organic phase; (b) two-phase emulsion after 4 days left in repose in a separation funnel. 

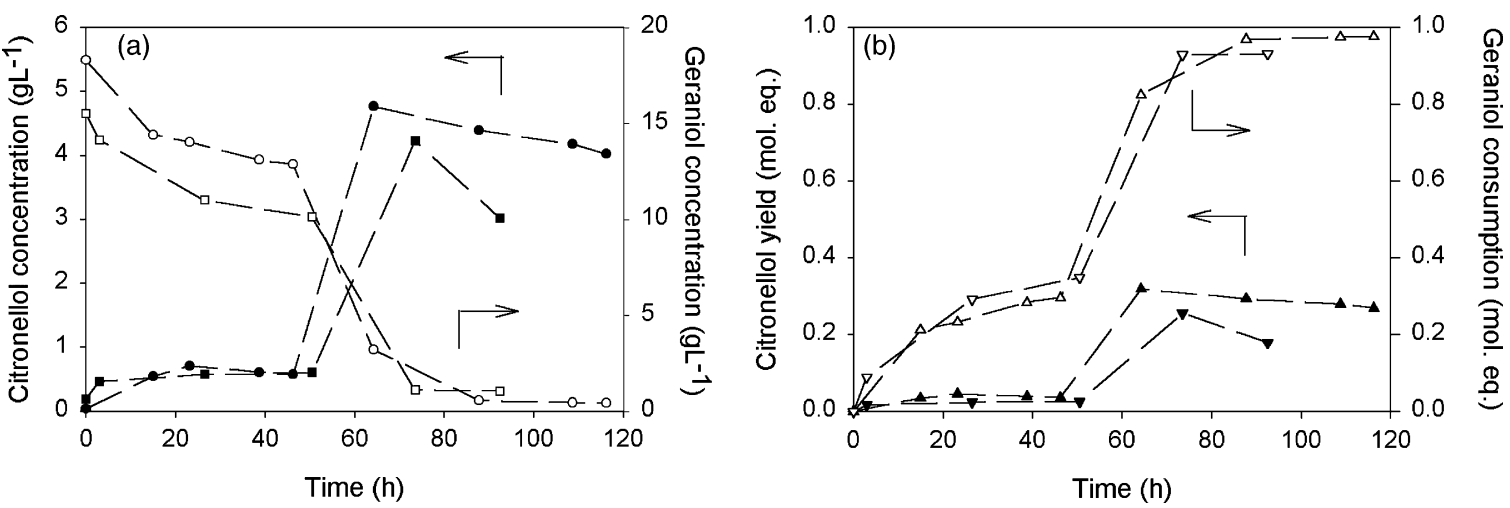

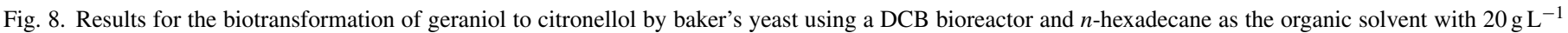

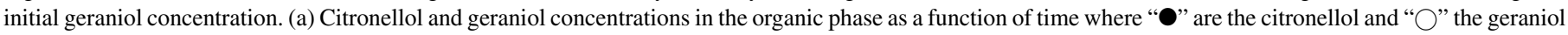

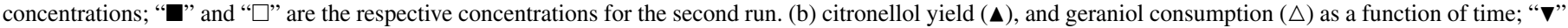
and " $\nabla$ " are the respective values for the second run.

[44] reported that toluene at concentrations of $0.5,1.0$ and $2.0 \%$ (v/v) completely killed baker's yeast cells. Therefore, we can conclude that toluene cannot be used as the organic phase in a DCB system. Despite this, a DCB bioreactor using toluene will be used in later work as a control test.

\section{DCB bioreactor}

A batch DCB bioreactor was employed for carrying out the model biotransformation. The reaction was performed with baker's yeast cells working in a resting mode; i.e., non-growing. $n$-Hexadecane and toluene were used as the organic phases, the latter as a control. A strong emulsion was formed in these reactors (Fig. 7) and the organic phase was difficult to recover even after centrifugation as will be discussed below.

As expected from the observations in the shake-flask tests, the DCB toluene reactor completely inhibited the biotransformation and no citronellol production was detected. It appears that the direct contact with the toluene phase destroyed the baker's yeast cells since the biomass aggregated at the surface of the reactor mixture.

When $n$-hexadecane was used as the organic phase, low production of citronellol and oxygen consumption were observed for the first $48 \mathrm{~h}$. After this productivity lag-phase - which refers to a catalytically inactive period rather than to a cell growth phase - the biotransformation progressed at a specific reaction rate comparable to the literature [32], approximately $250 \mathrm{nmol} \mathrm{min}^{-1} \mathrm{~g} \mathrm{biomass}^{-1}$ (Fig. 8a). The two repeats of this experiment showed similar lag-phase periods for citronellol production and geraniol consumption (Fig. 8b). The average maximum yield for the first two runs was calculated as 0.3 mol equiv. A similar yield was reported by Gramatica et al. using a dense suspension of baker's yeast resting cells $\left(1 \times 10^{8} \mathrm{cell} \mathrm{mL}^{-1}\right)$ in a single-phase aqueous biotransformation [31].

Geraniol was almost depleted after the maximum productivity period. Then, the production of citronellol stopped and its concentration slowly decreased (Fig. 8a and b) probably due to further reaction of the product mediated by the biocatalyst or by the components of the biomedium.
Husken et al. [45] also observed a productivity lag period in the two-phase biotransformation of 3-methylcatechol from toluene using 1-octanol as the organic phase; however they observed no lag-phase in a single-phase aqueous reactor [46]. Schwartz and Mccoy [47] also reported a productivity delay in the epoxidation of 1,7-octadiene by growing Pseudomonas oleovorans with cyclohexane as the organic phase. Despite this long delay, they reported that all the biotransformations were eventually completed. In conclusion, the productivity lag-phase in DCB reactors is an adaptation period of the biocatalyst to the new aqueous/organic medium $[45,47,48]$.

\section{Mass transfer tests}

The first step to assess the feasibility of employing OSN membranes in the MBB was to characterise the transport of the model substrate and product in an OSN membrane biphasic system using $n$-hexadecane or toluene as the organic phase. Table 1 includes the organic/aqueous partition coefficients $\left(m_{\text {org/aq }}\right)$ of citronellol and geraniol for these solvents. The results for the measurements of the OMTC of the different solute-solvent systems are listed in Table 2.

Although in general the OMTC obtained in our system were lower than those reported by Doig et al. for a non-porous silicone membrane, they still fall in the OMTC range reported in the literature for large scale applications $\left(0.1-5.0 \times 10^{-6} \mathrm{~m} \mathrm{~s}^{-1}\right)$ [49-52].

As will be shown below, Eqs. (7b) and (8) underestimated the liquid mass transfer coefficients. This inconsistency of Leveque correlation had been reported previously [37,53,54]. In contrast, Eq. (7c), resulted in values consistent with the resistance-in-series model for the mass transfer data; thus, it was further used to calculate the mass transfer resistances (Table 3).

Using the resistance in series model (Eq. (3)) and Eq. (7c), we calculated the mass transfer resistances for the organic liquid $\left(m_{\text {org } / \text { aq }} k_{\text {org }}\right)^{-1}$, the aqueous liquid, $k_{\text {aq }}^{-1}$, as well as for the membrane $\left(m_{\mathrm{m} / \mathrm{aq}} k_{\mathrm{m}}\right)^{-1}$, and report them as the percentage of the overall mass transfer resistance, $K_{\text {aq }}^{-1}$. 
Table 2

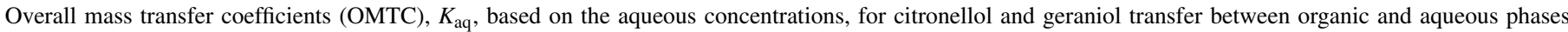
through a Starmem ${ }^{\mathrm{TM}} 122$ membrane $^{\mathrm{a}}$

\begin{tabular}{|c|c|c|c|}
\hline Solute & Solvent & $K_{\mathrm{aq}}$, OMTC $\left(\times 10^{7} \mathrm{~m} \mathrm{~s}^{-1}\right)$ & Mass balance (\%) \\
\hline \multirow{2}{*}{ Citronellol } & Toluene & $26.7(28.7,24.7)$ & $\mathbf{9 3}(94,91)$ \\
\hline & $n$-Hexadecane & $\mathbf{1 5 . 9}(15.8,16.6,15.2)$ & $87(79,86,96)$ \\
\hline \multirow{2}{*}{ Geraniol } & Toluene & $\mathbf{4 5 . 9}(40.2,51.5)$ & $99(100,99)$ \\
\hline & $n$-Hexadecane & $\mathbf{6 . 9}(6.4,8.4,5.8)$ & $77(63,96,71)$ \\
\hline
\end{tabular}

a Averages in bold and individual experimental values in parenthesis.

The OMTCs of both solutes were significantly higher in toluene than in $n$-hexadecane. The percentages of mass transfer resistance for both solvents were below $1 \%$, so the organic liquid film resistance was neglected (Table 3). From the estimations in Table 3 we can conclude that the lower OMTCs for $n$-hexadecane than for toluene were due to a significantly higher membrane resistance in the $n$-hexadecane systems. Considering that the membrane is comprised of the membrane material and the embedded organic solvent, two main factors caused this effect: (i) the lower $m_{\mathrm{org} / \mathrm{aq}}$ of the solutes in $n$-hexadecane; and (ii) the higher viscosity of $n$-hexadecane ( $3.0 \mathrm{mPas}$ [55]) compared to toluene $(0.6 \mathrm{mPa}$ s [55]) yielding lower diffusion coefficients for the former.

Additionally, in the toluene experiments the OMTCs of geraniol were higher than those of citronellol, opposite to the $n$-hexadecane runs. In the case of $n$-hexadecane, the system with geraniol suffered a higher membrane resistance contribution than the citronellol system (Table 3). Considering that the membrane is comprised of both membrane material and absorbed solvent, the partition $m_{\text {org/aq }}$ played the major effect on the OMTC; i.e., the solute with greatest $m_{\text {org/aq }}$ in $n$-hexadecane (citronellol) resulted in the highest OMTC.

On the other hand, in the case of the toluene systems, citronellol had the lowest OMTC even though its $m_{\text {org/aq }}$ in toluene is higher than that of geraniol. However, the membrane resistance of the geraniol system was much lower than that for citronellol. This indicates that in the toluene systems the $m_{\text {org }}$ aq was not the only factor affecting the OMTC; and other variables such as the diffusivities (in the membrane) and membrane/aqueous partition coefficients, $m_{\mathrm{m} / \mathrm{aq}}$, for the two solutes may be important.

Table 3

Estimated contribution of the individual resistances to the overall mass transfer resistance (\%) for the transport of geraniol and citronellol from organic solvent to aqueous phase in a flat-sheet membrane cell

\begin{tabular}{lccccc}
\hline Parameter & \multicolumn{2}{l}{$n$-Hexadecane } & & \multicolumn{2}{l}{ Toluene } \\
\cline { 2 - 3 } \cline { 6 - 6 } \cline { 6 - 6 } & Geraniol & Citronellol & & Geraniol & Citronellol \\
\hline$R e_{\text {org }}$ & 26.8 & 26.8 & & 171.5 & 171.5 \\
$k_{\text {aq }}\left(\times 10^{6} \mathrm{~m} \mathrm{~s}^{-1}\right)$ & 5.3 & 5.2 & & 5.3 & 5.2 \\
$k_{\text {org }}\left(\times 10^{6} \mathrm{~m} \mathrm{~s}^{-1}\right)$ & 2.2 & 2.1 & & 5.2 & 5.1 \\
\%Organic liquid film & 0.7 & 0.7 & & 0.3 & 0.1 \\
\%Aqueous liquid film & 13.1 & 30.7 & & 87.0 & 51.6 \\
\%Membrane & 86.2 & 68.6 & & 12.7 & 48.3 \\
\hline
\end{tabular}

Two organic solvents were used: $n$-hexadecane and toluene. (Liquid mass transfer coefficients were calculated using Eq. (7c) $)\left(R e_{\mathrm{aq}}=809\right)$.
An additional experiment was performed to assess the adequacy of the correlations tested. Two flow rate levels were used: High (aqueous: $95 \mathrm{~L} \mathrm{~h}^{-1}$, organic: $18 \mathrm{Lh}^{-1}$ ) and Low (aqueous: $50 \mathrm{Lh}^{-1}$, organic: $9 \mathrm{~L} \mathrm{~h}^{-1}$ ); toluene was used as the organic solvent. Eqs. (7b) and (8) resulted inconsistent with the resistance-in-series equation (Table 4). According to these correlations the total resistance was affected mostly by the aqueous liquid film for both flow-rate levels. However, after doubling the Re number for both liquids (Table 4), the OMTC did not change significantly (with $95 \%$ confidence interval) for the High and Low flow rate levels tested (Fig. 9). So we can conclude that these equations could not account adequately for the contribution of the membrane to the mass transfer resistance. It is noteworthy that when the $R e$ numbers of both liquids were doubled (thus reducing the aqueous resistance) the contribution of the membrane resistance increased significantly from 3 to $15 \%$ (Table 4 , Eq. (7c)).

\section{Membrane bioreactor for biotransformation (MBB)}

An MBB was developed to overcome the main problem associated with DCB bioreactors: formation of two-phase emulsions.

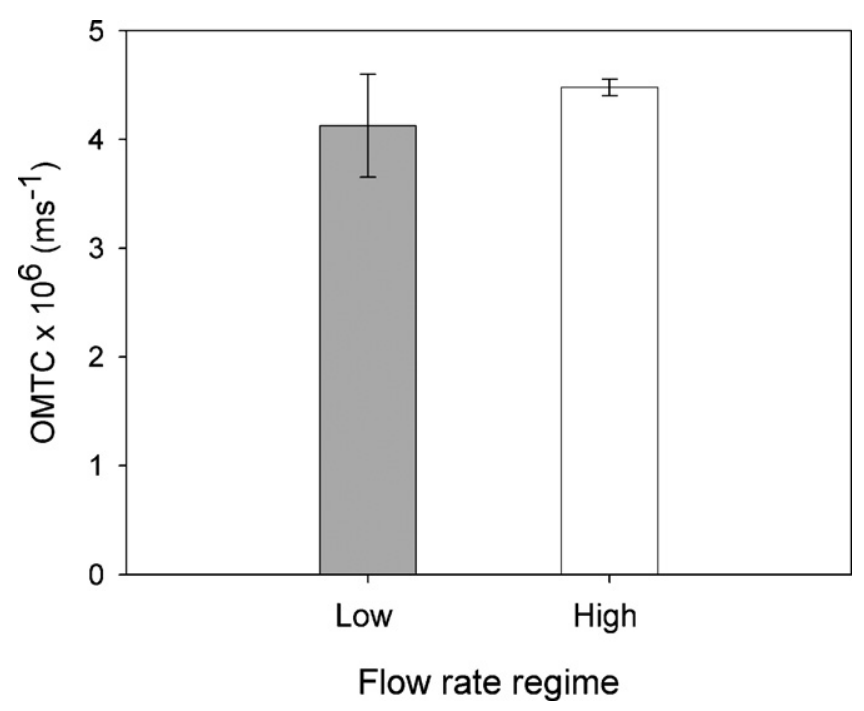

Fig. 9. Overall mass transfer coefficient (OMTC) of geraniol from the toluene organic phase $\left(60 \mathrm{~g} \mathrm{~L}^{-1}\right)$ to an aqueous phase (based on the aqueous phase concentrations) through a Starmem ${ }^{\mathrm{TM}} 122$ membrane. An aqueous/organic volume ratio of 10:1 was used ( $1 \mathrm{~mL}: 0.1 \mathrm{~mL})$ : two different flow rate levels were used: High (aqueous: $95 \mathrm{~L} \mathrm{~h}^{-1}$, organic: $18 \mathrm{~L} \mathrm{~h}^{-1}$ ) and Low (aqueous: $50 \mathrm{~L} \mathrm{~h}^{-1}$, organic: $\left.9 \mathrm{~L} \mathrm{~h}^{-1}\right)$. 
Table 4

Effect of the flow rate regime on the mass transfer resistances for geraniol from toluene to aqueous in the "reduced volume" mass-transfer membrane cell

\begin{tabular}{|c|c|c|c|c|c|c|}
\hline \multirow[t]{3}{*}{$\%$ Mass transfer resistance } & \multicolumn{6}{|c|}{ Flow rate regime ${ }^{a}$} \\
\hline & \multicolumn{3}{|c|}{ Low $\left(R e_{\mathrm{aq}}=426, R e_{\mathrm{org}}=115\right)$} & \multicolumn{3}{|c|}{$\operatorname{High}\left(R e_{\mathrm{aq}}=809, R e_{\mathrm{org}}=229\right)$} \\
\hline & Eq. (7b) & Eq. (7c) & Eq. (8) & Eq. (7b) & Eq. $(7 c)$ & Eq. (8) \\
\hline \%Aqueous liquid film & ID & 96.7 & ID & ID & 84.6 & 89.0 \\
\hline \%Organic liquid film & 0.2 & 0.2 & 0.3 & 0.2 & 0.2 & 0.2 \\
\hline$\%$ Membrane & ID & 3.1 & ID & ID & 15.2 & 10.8 \\
\hline
\end{tabular}

${ }^{a}$ ID: indefinite value.

Additionally, an ideal MBB needs to provide acceptable mass transfer rates of substrate and product for the biotransformation to take place at volumetric productivities comparable to the DCB reactors.

Two different runs were carried out with $n$-hexadecane as the organic phase and $20 \mathrm{~g} \mathrm{~L}^{-1}$ geraniol initial concentration. The first MBB configuration (MBB-HD1) used a $2000 \mathrm{~mL}: 200 \mathrm{~mL}$ aqueous/organic volume ratio. A maximum product concentration $\left(1.6 \mathrm{~g} \mathrm{~L}^{-1}\right)$ in the organic phase was obtained at about $75 \mathrm{~h}$ (Fig. 10A1). In a second MBB hexadecane experiment, MBB-HD2, an aqueous/organic volume ratio of $600 \mathrm{~mL}: 60 \mathrm{~mL}$ was used to reduce the reactor volume; thus improving solute mass transfer through the membrane by providing more membrane area per reactor volume. The citronellol concentration increased continuously from the start of the experiment until it reached a maximum concentration of $1.9 \mathrm{~g} \mathrm{~L}^{-1}$ at about $68 \mathrm{~h}$, when the reaction stopped (Fig. 10A1). Additionally, whereas the citronellol yield followed a similar pattern to that of the MBB-HD1 experiment, the geraniol consumption was much lower (Fig. 10A2).

Finally an MBB experiment was conducted using toluene as the organic phase (MBB-Tol) and $60 \mathrm{~g} \mathrm{~L}^{-1}$ geraniol initial concentration. This concentration was three times higher than that used in the $n$-hexadecane system to provide a sufficient driving force for substrate transport to the aqueous phase. The MBB-Tol occurred at two different reaction rates, an initial slow productivity period was followed by an increase in the reaction rate at $48 \mathrm{~h}$. Then, the reaction progressed steadily (Fig. 10B1) until it
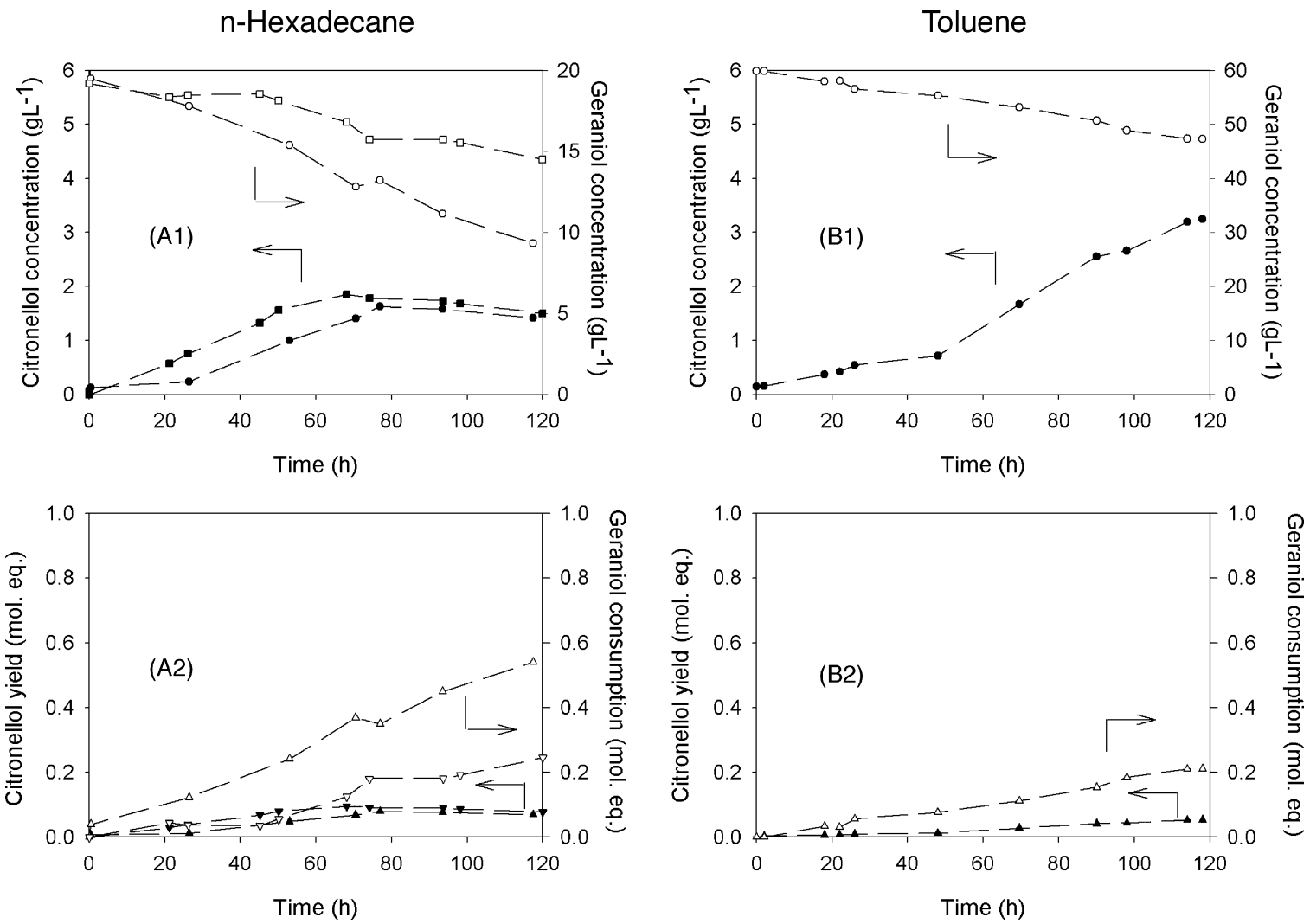

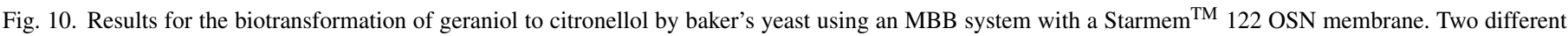

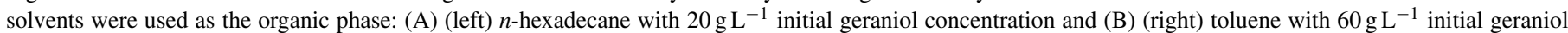

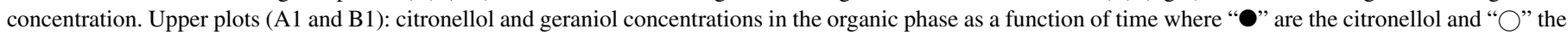

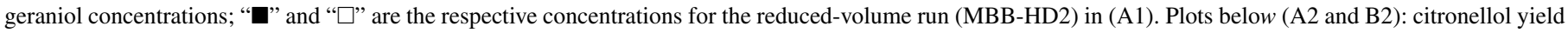
$(\boldsymbol{\Delta})$, and geraniol consumption $(\triangle)$ as a function of time; and " $\nabla$ " and " $\nabla$ " were used for the respective values of the MBB-HD2 run in (A2). 
Table 5

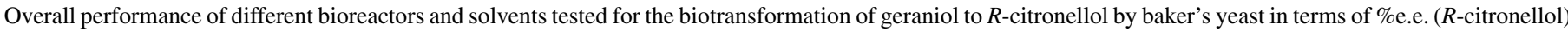
and volumetric productivities

\begin{tabular}{|c|c|c|c|}
\hline Organic solvent & Reactor system & $\begin{array}{l}\text { Maximum volumetric productivity } \\
\left(\mathrm{mg} \mathrm{L}^{-1} \mathrm{~h}^{-1}\right)\end{array}$ & $R$-Citronellol \%e.e. \\
\hline \multirow{2}{*}{ Toluene } & DCB & $\approx 0$ & - \\
\hline & MBB-Tol & 2.8 & 32.7 \\
\hline \multirow{3}{*}{$n$-Hexadecane } & DCB & $6.4(5.5,7.4)$ & 85.5 \\
\hline & MBB-HD1 & 2.1 & 82.1 \\
\hline & MBB-HD2 (reduced volume) & 3.1 & 68.5 \\
\hline
\end{tabular}

reached a maximum citronellol concentration of $4.25 \mathrm{~g} \mathrm{~L}^{-1}$ at $170 \mathrm{~h}$ (data not shown). This concentration was higher than that obtained in the MBB-HD runs, and it is comparable to the concentrations obtained in the DCB hexadecane experiments. The yield in this experiment (Fig. 10B2) was rather low due to the high initial substrate concentration, but the ratio of the productyield to substrate-consumption was 0.24 , a value comparable to the MBB-HD1 run (0.23).

\section{Overall analyses of the bioreactor performance}

The highest maximum volumetric productivity was achieved in the hexadecane DCB system which was 2-3 times higher than those obtained in the MBB reactors (Table 5). The only report in the literature for the e.e. of the model reaction [31], determined the production of pure $R$-citronellol (100\% e.e.), analysed by NMR (chiral lanthanide shift reagent) and GLCMS. Nevertheless, the maximum $R$-citronellol e.e. measured in this work was only $85.5 \%$ (Table 5 ).

Cappaert and Larroche [41] observed a decrease in the product e.e. during the reduction of 2-heptanol by baker's yeast in an $n$-hexadecane DCB reactor. The product e.e. dropped from $99 \%$, during the first $15 \mathrm{~h}$, to about $80 \%$ e.e. at the end of the process $(60 \mathrm{~h})$. They attributed the e.e. decrease to the activation of further biocatalyst dehydrogenases with opposite enantioselectivity as the reaction progressed. Considering that the e.e. was only measured at the end of the run, a similar decrease in the e.e. possibly occurred in our system.

In the first MBB experiment with $n$-hexadecane, MBBHD1, with a $2000 \mathrm{~mL}: 200 \mathrm{~mL}$ aqueous/organic volume ratio, the maximum volumetric productivity was about three times lower than that for the DCB reactor (Table 5). The final e.e. of the MBB-HD1 product was close to that obtained in the DCB experiments, so the enantiomeric specificity of the reaction was not affected by the direct contact of $n$-hexadecane with the cells.

Considering that no citronellol production was obtained when toluene was used as the organic phase in the DCB bioreactor, it was remarkable to observe a higher volumetric productivity for the MBB using toluene (MBB-Tol) than that of the corresponding MBB-HD1 run (Table 5). This was due mainly to the membrane preventing the solvent coming into direct contact with the biocatalyst, thus avoiding biocatalyst inactivation. In addition, in this case the contribution of the membrane to $K_{\mathrm{aq}}^{-1}$ was lower than that of the $n$-hexadecane systems (Table 3 ).
Unfortunately, the product e.e. in the MBB-Tol run was considerably lower compared to that obtained in either of the $n$ hexadecane systems (Table 5). The reason for this might be that toluene diffused to the aqueous side $\left(40 \mathrm{mg} \mathrm{L}^{-1}\right.$ average aqueous concentration) thus altering the cell enzymes and reducing the biocatalyst enantioselectivity. In addition, the toluene concentration constantly present in the aqueous phase may have caused the productivity lag-phase observed in this run. This lagphase was, however, less pronounced than those observed in the hexadecane DCB systems. On the other hand, in contrast to the $\mathrm{DCB}$ reactor, the hexadecane $\mathrm{MBBs}$ did not present a lag-phase period. This positive result for the MBB system may be caused by the separation of the aqueous and organic phases during the reaction.

The MBB-HD1 experiment was mass-transfer limited since its volumetric productivity was much lower than that of the DCB runs, with the membrane making a major contribution to the overall mass transfer resistance as discussed above. Thus one of the membrane cells was modified in order to increase the membrane area per working volume from 0.75 to $2.5 \mathrm{~m}^{2} \mathrm{~m}^{-3}$ by reducing the aqueous/organic volume ratio to $600 \mathrm{~mL}: 60 \mathrm{~mL}$. The aim was to drive the MBB reactor to a kinetically limited system. With this redesign the maximum volumetric productivity of the new system, MBB-HD2, increased from 2.1 to $3.1 \mathrm{mg} \mathrm{L}^{-1} \mathrm{~h}^{-1}$. Although this result was still two times lower than the DCB volumetric productivity, it was higher than the value obtained in the MBB-Tol experiment. The reduced-volume system also seemed to be mass-transfer limited since the aqueous geraniol concentration sharply dropped after $20 \mathrm{~h}$ of reaction and it did not rise again (Fig. 11).

Geraniol consumption continued to increase after $60 \mathrm{~h}$ of reaction in the MBB-HD2 run (Fig. 10A2). So the reason for the low level of geraniol in the aqueous phase (Fig. 11) - even after citronellol production stopped at about $60 \mathrm{~h}$ - may be that the baker's yeast continued consuming geraniol for metabolic reactions other than those leading to citronellol production. Two alternatives for geraniol utilisation by baker's yeast have been reported: (1) biotransformation of geraniol to linalool and $\alpha$ terpineol [56]; (2) utilisation of geraniol for the biosynthesis of sterols [57].

The e.e. for the MBB-HD2 reactor was lower than that for the first MBB-HD1 run (Table 5). This was probably due to the presence of toluene in the organic phase remaining from the membrane preconditioning stage. After washing the preconditioning solvent (toluene) with $n$-hexadecane, prior to the 


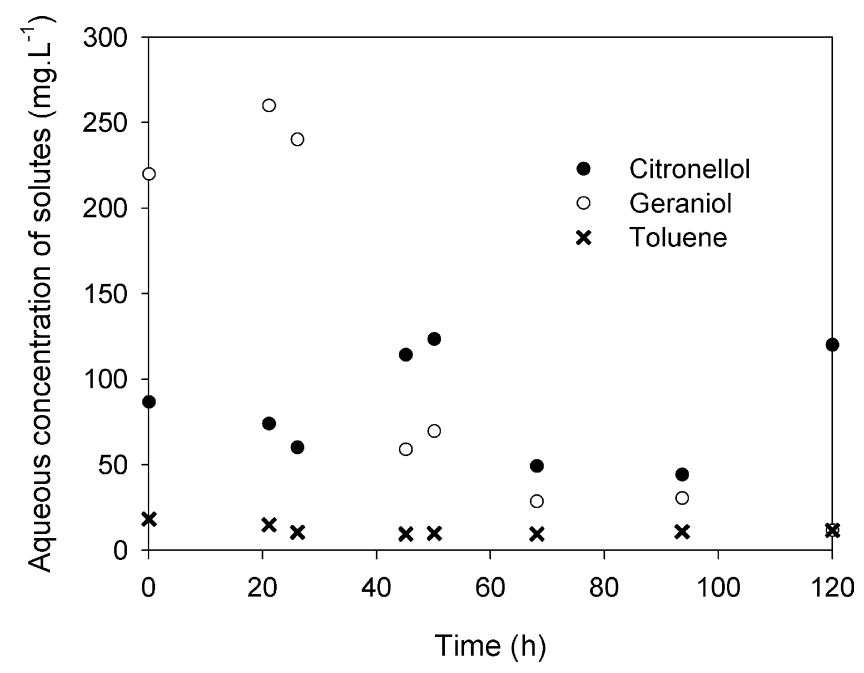

Fig. 11. Aqueous phase concentrations of organic solutes (citronellol, geraniol and toluene) in the organic phase during the reduced-volume $n$-hexadecane experiment, MBB-HD2 (600 mL:60 mL aqueous/organic volume ratio).

MBB-HD2 run, some toluene remained in the system, and a small aqueous concentration of toluene $\left(12 \mathrm{mg} \mathrm{L}^{-1}\right.$, average), was detected during all the run (Fig. 11). Since the biocatalyst enantioselectivity is very sensitive to the presence of toluene, as discussed above, the low aqueous toluene concentration may have reduced the enantioselectivity of the biotransformation.

It appears that for the reactors using $n$-hexadecane, there is a short active biocatalyst lifetime $(70-80 \mathrm{~h})$ in which baker's yeast is able to produce citronellol; if the substrate is not supplied during this time, the yeast begins to catalyse other reactions. However, the MBB-Tol showed a very long biocatalyst active period (about $140 \mathrm{~h}$ ) compared to the $n$-hexadecane reactors. Apparently, this result can only be attributed to the organic-phase effect on the biocatalyst. Since the $m_{\text {org/aq }}$ of citronellol and geraniol in toluene are about 4 and 7 times those in $n$-hexadecane, respectively, the solute aqueous concentrations remained higher in the latter solvent. For example, in the $n$-hexadecane and toluene systems the maximum geraniol aqueous concentrations were 300 and $170 \mathrm{mg} \mathrm{L}^{-1}$, and the average citronellol aqueous concentrations 100 and $20 \mathrm{mg} \mathrm{L}^{-1}$, respectively. In this respect, Bard et al. [58] reported that geraniol inhibits baker's yeast viability by altering the cellular membrane. So the higher amount of substrate and product in the aqueous phase for the $n$-hexadecane bioreactors reduced the stability and active lifetime of the biocatalyst.

\section{Solvent recovery from DCB mixtures}

Although the hexadecane DCB experiments yielded the highest volumetric productivities, the main problem in this type of reactor is the formation of a stable emulsion of the organic and aqueous phases. The emulsified mixture represents an important practical issue for the downstream separation and product recovery; moreover in the case of $n$-hexadecane which possesses a very high boiling point $\left(287^{\circ} \mathrm{C}\right)$. A standard procedure which

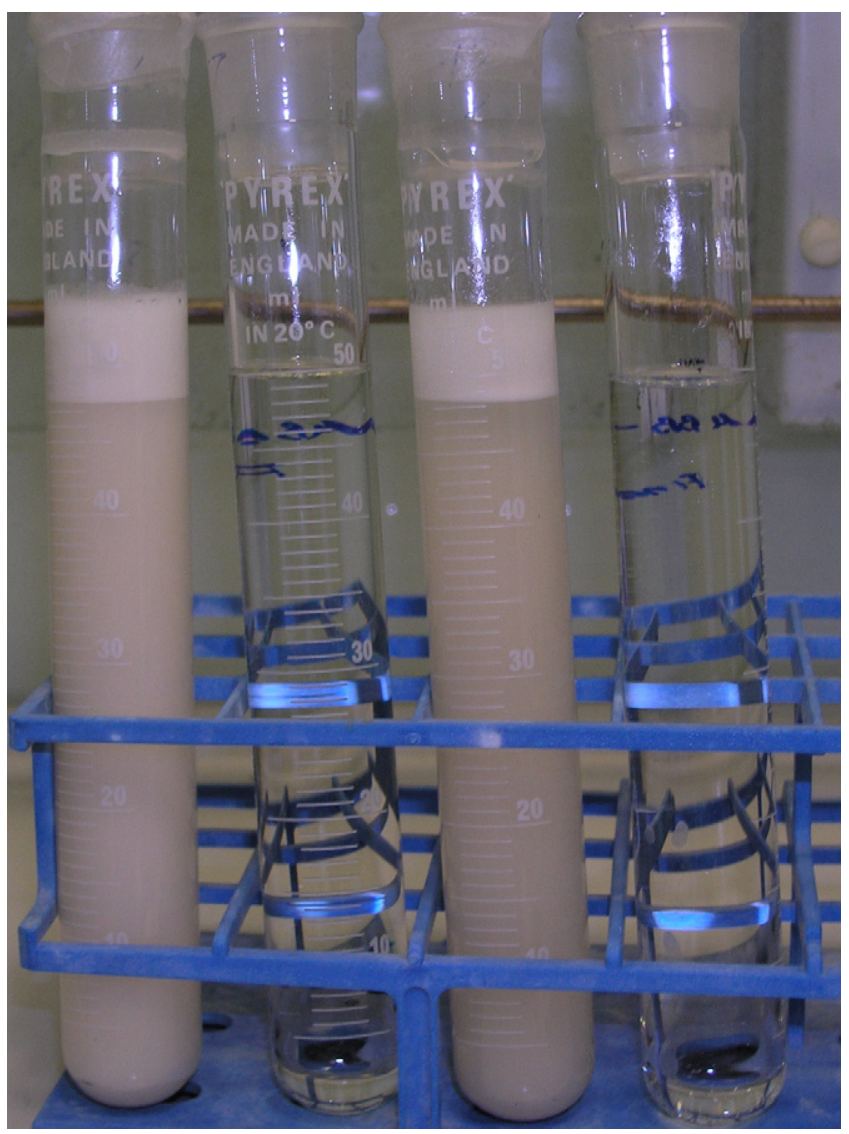

Fig. 12. Comparison of the final products obtained from $\mathrm{DCB}$ and $\mathrm{MBB}$ systems: (A) DCB-toluene, (B) MBB-toluene, (C) DCB-hexadecane and (D) MBB-hexadecane.

may be used for the separation of the two phases is centrifugation. Here we carried out such a separation at $8500 \times \mathrm{g}$ in order to quantify the recovery of the organic phase and to assess the practicability of the process.

Fig. 12 shows a comparison of the DCB mixtures (after 1 h settling) and the MBB final product samples. Evidently the quality of the MBB products was much higher than that of the DCB mixtures in terms of product cleanness and the additional separation processing needed for the latter. Even after the DCB mixtures were centrifuged, the aqueous and organic phases could not be completely separated: a white emulsified interface remained. The recovery of the organic phase was quantified as 45.5 and $57.7 \%(\mathrm{v} / \mathrm{v})$ for the toluene and $n$-hexadecane solvents, respectively. The final solvent recovery was not only difficult to obtain but also very low.

\section{Comparison to other membrane bioreactors}

Doig et al., using a silicone rubber MBB for the same model biotransformation described here, obtained a volumetric productivity similar to that of a DCB bioreactor [32]. The mass transfer rates obtained in their reactor were about 10 times higher than those measured in the hexadecane OSN-MBB. Paradoxically, whereas the high mass transfer rate in their system was due to the high swelling of silicone rubber in contact with organic sol- 
vents, the main disadvantage of using this material is that its high swelling causes membrane cracks and tears, which eventually can lead to phase breakthrough and emulsion formation.

On the other hand, aqueous breakthrough, the main drawback of microporous MBB reactors, was not observed in the OSN-MBB system. In microporous MBBs, the breakthrough pressure is dramatically decreased by the presence of surfactants in the biomedium which reduces the surface tension between the two liquid phases [4-6,11,12]. Han et al. reported a 30 bar breakthrough pressure in MPF 50, an OSN composite membrane [34], which is very much above the maximum pressure attainable in our system $(0.4 \mathrm{bar})$. Considering the surfactantadsorption mechanism for the reduction of the breakthrough pressure outlined by Shroen et al. [12] and Vaidya et al. [11], a decrease in this pressure due to the presence of surfactants in the biomedium, such as enzymes, seems unlikely to occur in the OSN-MBB because the nano-scale of the membrane pores prevents adsorption of surfactants into the pore walls.

\section{Conclusions}

A new approach was presented for a biphasic biotransformation model of hydrophobic molecules using a membrane bioreactor for biotransformations (MBB) and organic solvent nanofiltration (OSN) membranes. The new system was successfully employed as a strategy for in situ substrate addition to, and product removal from the bioreactor. The proposed reactor avoids the formation of emulsions and mitigates the solvent toxicity observed in direct contact biphasic (DCB) reactors, thus expanding the range of solvents that can be used to assist biotransformations. For example, it was possible to use toluene in the OSN-MBB as the organic solvent of the model reaction, whereas no biocatalyst activity occurred when this solvent was used in a DCB reactor. Additionally, the use of OSN membranes overcomes the problems of phase breakthrough and poor membrane organic solvent resistance, previously observed in microporous and non-porous MBBs, respectively. However, the OSN-MBB resulted in 2-3 times lower volumetric productivities than those of the DCB reactor due to limitations in the substrate transfer rate through the membrane. Nevertheless, the OSN-MBB produced a much cleaner final product than that of the DCB reactor. Further studies will aim at improving solute transport rates in the OSN-MBB system by increasing the membrane overall mass transfer coefficient or the membrane area per reactor volume.

\section{Acknowledgments}

R. Valadez-Blanco wants to gratefully acknowledge Conacyt, from the government of Mexico, for the financial support towards the realisation of this work, grant number 161434. F.C. Ferreira would like to thank financial support from Fundação para a Ciência e a Tecnologia (SFRH/BPD/19369/2004). We wish to acknowledge the use of the EPSRCs Chemical Database Service at Daresbury.

\begin{tabular}{|c|c|}
\hline \multicolumn{2}{|c|}{ Nomenclature } \\
\hline A & membrane surface area $\left(\mathrm{m}^{2}\right)$ \\
\hline & $\begin{array}{l}\text { mass of microorganisms in bioreactor } \\
\text { (g biomass) }\end{array}$ \\
\hline$C_{\mathrm{n}}$ & solute concentration in phase $\mathrm{n}_{\left(\mathrm{g} \mathrm{L}^{-1}\right)}$ \\
\hline$C_{\mathrm{n}}^{*}$ & $\begin{array}{l}\text { solute concentration in equilibrium at the } \mathrm{n} \text { inter- } \\
\text { face }\left(\mathrm{g} \mathrm{L}^{-1}\right)\end{array}$ \\
\hline$d_{\mathrm{e}}$ & equivalent diameter $(\mathrm{m})$ \\
\hline$D_{\mathrm{AB}}$ & $\begin{array}{l}\text { diffusion coefficient for the solute } A \text { into the liq- } \\
\text { uid } B\left(\mathrm{~m}^{2} \mathrm{~s}^{-1}\right)\end{array}$ \\
\hline$J$ & total flux of solute at an interface $\left(\mathrm{g} \mathrm{s}^{-1}\right)$ \\
\hline$k_{\mathrm{n}}$ & $\begin{array}{l}\text { individual mass transfer coefficient in the } \mathrm{n} \text { phase } \\
\left(\mathrm{m} \mathrm{s}^{-1}\right)\end{array}$ \\
\hline$K_{\mathrm{aq}}$ & $\begin{array}{l}\text { overall mass transfer coefficient based on the } \\
\text { aqueous phase concentration }\left(\mathrm{m} \mathrm{s}^{-1}\right)\end{array}$ \\
\hline$L$ & membrane cell length $(\mathrm{m})$ \\
\hline$m_{\mathrm{m} / \mathrm{n}}$ & partition coefficient between the $m$ and $n$ phases \\
\hline$M_{\mathrm{B}}$ & molecular weight of liquid $\mathrm{B}\left(\mathrm{g} \mathrm{mol}^{-1}\right)$ \\
\hline$M_{\mathrm{w}}$ & molecular weight $\left(\mathrm{g} \mathrm{mol}^{-1}\right)$ \\
\hline$N_{\mathrm{n}}$ & flux of solute in the $\mathrm{n}$ phase $\left(\mathrm{g} \mathrm{s}^{-1}\right)$ \\
\hline$P$ & $\begin{array}{l}\text { product number of moles ( } R \text { or } S \text { enantiomer) } \\
(\mathrm{mol})\end{array}$ \\
\hline$R e_{\mathrm{n}}$ & Reynolds number for the $\mathrm{n}$ liquid phase \\
\hline$S$ & final substrate number of moles (mol) \\
\hline Sc & Schmidt number \\
\hline $\mathrm{SC}$ & substrate consumption (mol equiv.) \\
\hline$S h$ & Sherwood number \\
\hline$S_{0}$ & initial substrate number of moles (mol) \\
\hline$t$ & time (h) \\
\hline$T$ & temperature $(\mathrm{K})$ \\
\hline VP & volumetric productivity $\left(\mathrm{mg} \mathrm{L}^{-1} \mathrm{~h}^{-1}\right)$ \\
\hline$V_{\mathrm{A}}$ & molar volume of solute $\mathrm{A}\left(\mathrm{m}^{3} \mathrm{~kg} \mathrm{~mol}^{-1}\right)$ \\
\hline$V_{\mathrm{n}}$ & volume of liquid in phase $\mathrm{n}(\mathrm{L})$ \\
\hline$Y$ & product yield (mol equiv.) \\
\hline \multicolumn{2}{|c|}{ Greek letters } \\
\hline$\mu$ & liquid viscosity (Pa s) \\
\hline$v$ & linear liquid velocity $\left(\mathrm{m} \mathrm{s}^{-1}\right)$ \\
\hline$\rho$ & liquid density $\left(\mathrm{kg} \mathrm{m}^{-3}\right)$ \\
\hline$\phi_{\mathrm{B}}$ & association factor of liquid B \\
\hline \multicolumn{2}{|c|}{ Subscripts } \\
\hline $\mathrm{aq}$ & aqueous \\
\hline A & diffusing solute \\
\hline B & diffusing solvent \\
\hline org & organic \\
\hline $\mathrm{m}$ & membrane \\
\hline
\end{tabular}

\section{References}

[1] K. Faber, Biotransformations in Organic Chemistry, Spinger-Verlag, Berlin, 2004

[2] P. D'Arrigo, G. Pedrocchi-Fantoni, S. Servi, Stereoselective synthesis of chiral compounds using whole-cell biocatalysts, in: R.N. Patel (Ed.), Stereoselective Biocatalysis, M. Dekker, New York, 2000, pp. 365-396. 
[3] M. Held, A. Schmid, J.B. van Beilen, B. Witholt, Biocatalysis. Biological systems for the production of chemicals, Pure Appl. Chem. 72 (7) (2000) 1337-1343.

[4] M.M. Hoq, T. Yamane, S. Shimizu, T. Funada, S. Ishida, Continuous synthesis of glycerides by lipase in a microporous membrane bioreactor, J. Am. Oil Chem. Soc. 61 (4) (1984) 776-781.

[5] W. Pronk, P.J.A.M. Kerkhof, C. Vanhelden, K. Vantriet, The hydrolysis of triglycerides by immobilized lipase in a hydrophilic membrane reactor, Biotechnol. Bioeng. 32 (4) (1988) 512-518.

[6] W. Pronk, K. Vantriet, The interfacial behavior of lipase in free form and immobilized in a hydrophilic membrane reactor, Biotechnol. Appl. Biochem. 14 (2) (1991) 146-154.

[7] A. Kiani, R.R. Bhave, K.K. Sirkar, Solvent-extraction with immobilized interfaces in a microporous hydrophobic membrane, J. Membr. Sci. 20 (2) (1984) 125-145.

[8] R. Prasad, K.K. Sirkar, Dispersion-free solvent-extraction with microporous hollow-fiber modules, AIChE J. 34 (2) (1988) 177-188.

[9] R. Prasad, G.T. Frank, K. Sirkar, Nondispersive solvent extraction using microporous membranes, AIChE Symp. Series 84 (261) (1988) 4253.

[10] R. Prasad, K.K. Sirkar, Hollow fiber solvent-extraction of pharmaceutical products - a case-study, J. Membr. Sci. 47 (3) (1989) 235-259.

[11] A.M. Vaidya, P.J. Halling, G. Bell, Surfactant-induced breakthrough effects during the operation of 2-phase biocatalytic membrane reactors, Biotechnol. Bioeng. 44 (6) (1994) 765-771.

[12] C.G.P.H. Schroen, M.A. Cohenstuart, A. Vanderpadt, K. Vantriet, Minimum breakthrough pressure as a measure for wettability changes caused by protein adsorption at hydrophobic membranes, Bioseparation 4 (1994) $151-163$.

[13] S. Westgate, A.M. Vaidya, G. Bell, P.J. Halling, High specific activity of whole cells in an aqueous-organic two-phase membrane bioreactor, Enzyme Microb. Technol. 22 (7) (1998) 575-577.

[14] A. Liese, M. Karutz, J. Kamphuis, C. Wandrey, U. Kragl, Enzymatic resolution of 1-phenyl-1,2-ethanediol by enantioselective oxidation: overcoming product inhibition by continuous extraction, Biotechnol. Bioeng. 51 (5) (1996) 544-550.

[15] J.S. Shin, B.G. Kim, A. Liese, C. Wandrey, Kinetic resolution of chiral amines with omega-transaminase using an enzyme-membrane reactor, Biotechnol. Bioeng. 73 (3) (2001) 179-187.

[16] H.N. Chang, J.W. Yang, Y.S. Park, D.J. Kim, K.C. Han, Extractive ethanolproduction in a membrane cell recycle bioreactor, J. Biotechnol. 24 (3) (1992) 329-343.

[17] W.K. Kang, R. Shukla, K.K. Sirkar, Ethanol-production in a microporous hollow-fiber-based extractive fermenter with immobilized yeast 353 , Biotechnol. Bioeng. 36 (8) (1990) 826-833.

[18] R. Shukla, W. Kang, K.K. Sirkar, Acetone butanol ethanol (Abe) production in a novel hollow fiber fermenter extractor 354, Biotechnol. Bioeng. 34 (9) (1989) 1158-1166

[19] F. Molinari, F. Aragozzini, J.M.S. Cabral, D.M.F. Prazeres, Continuous production of isovaleraldehyde through extractive bioconversion in a hollow-fiber membrane bioreactor 352, Enzyme Microb. Technol. 20 (8) (1997) 604-611.

[20] S.D. Doig, A.T. Boam, A.G. Livingston, D.C. Stuckey, Mass transfer of hydrophobic solutes in solvent swollen silicone rubber membranes, J. Membr. Sci. 154 (1) (1999) 127-140.

[21] C. Linder, M. Nemas, N. Monosson, M. Perry, P. Tikua, R. Katraro, et al., inventors; Membrane Products Kiryat, assignee. Silicone-Derived Solvent Stable Membranes I. US patent 5,205,934 (1993).

[22] L.S. White, inventor; Grace W.R. \& Co., assignee. Polyimide Membrane for Separation of Solvents from Lube Oil. US patent 5,264,166 (1993).

[23] L.S. White, inventor; Grace W.R. \& Co., assignee. Polyimide Membranes for Hyperfiltration Recovery of Aromatic Solvents. US patent 6,180,008 B1 (2001).

[24] A. Livingston, L. Peeva, S.J. Han, D. Nair, S.S. Luthra, L.S. White, et al., Membrane separation in green chemical processing - solvent nanofiltration in liquid phase organic synthesis reactions, Adv. Membr. Technol. 984 (2003) 123-141.
[25] D.R. Machado, D. Hasson, R. Semiat, Effect of solvent properties on permeate flow through nanofiltration membranes. Part II. Transport model, J. Membr. Sci. 166 (1) (2000) 63-69.

[26] D.F. Stamatialis, N. Stafie, K. Buadu, M. Hempenius, M. Wessling, Observations on the permeation performance of solvent resistant nanofiltration membranes, J. Membr. Sci. 279 (1-2) (2006) 424-433.

[27] Y. Zhao, Q. Yuan, A comparison of nanofiltration with aqueous and organic solvents, J. Membr. Sci. 279 (1-2) (2006) 453-458.

[28] Y. Zhao, Q. Yuan, Effect of membrane pretreatment on performance of solvent resistant nanofiltration membranes in methanol solutions, J. Membr. Sci. 280 (1-2) (2006) 195-201.

[29] C. Linder, M. Nemas, N. Monosson, M. Perry, P. Tikua, R. Katraro, et al., inventors; Membrane Products Kiryat, assignee. Silicone-Derived Solvent Stable Membranes II. US patent 5,265,734 (1993).

[30] L.S. White, Transport properties of a polyimide solvent resistant nanofiltration membrane, J. Membr. Sci. 205 (1/2) (2002) 191-202.

[31] P. Gramatica, P. Manitto, B.M. Ranzi, A. Delbianco, M. Francavilla, Stereospecific reduction of geraniol to $(R)-(+)$-citronellol by Saccharomyces cerevisiae, Experientia 38 (7) (1982) 775-776.

[32] S.D. Doig, A.T. Boam, D.I. Leak, A.G. Livingston, D.C. Stuckey, A membrane bioreactor for biotransformations of hydrophobic molecules, Biotechnol. Bioeng. 58 (6) (1998) 587-594

[33] S.D. Doig, A.T. Boam, D.J. Leak, A.G. Livingston, D.C. Stuckey, Optimisation of the kinetics of the stereoselective reduction of geraniol to citronellol in a two liquid phase system, Biocatal. Biotransfor. 16 (1) (1998) 2744.

[34] S.J. Han, S.S. Luthra, L. Peeva, X.J. Yang, A.G. Livingston, Insights into the transport of toluene and phenol through organic solvent nanofiltration membranes, Sep. Sci. Technol. 389 (2003) 1899-1923.

[35] Y.H. See-Toh, F.C. Ferreira, A.G. Livingston, The influence of membrane formation parameters on the functional performance of organic solvent nanofiltration membranes, J. Membr. Sci. 299 (2007) 236-250.

[36] M.A. Leveque, Les lois de la transmission de chaleur par convection, Ann. Mines 13 (1928), 201, 305, 331.

[37] D.J. Pickett, Electrochemical Reactor Design, 2nd ed., Elsevier Scientific Publishing Company, Amsterdam, 1979.

[38] J. Qi, R.F. Savinell, Mass-transfer in a laminar-flow parallel plate electrolytic cell with simultaneous development of velocity and concentration boundary-layers, J. Appl. Electrochem. 20 (6) (1990) 885-892.

[39] C.R. Wilke, P. Chang, Correlation of diffusion coefficients in dilute solutions, AIChE J. 1 (2) (1955) 264-270.

[40] R.P. Perry, D.W. Green, Perry's Chemical Engineers' Handbook, 7th ed., McGraw-Hill International Editions, 1997.

[41] L. Cappaert, C. Larroche, Behaviour of dehydrated baker's yeast during reduction reactions in a biphasic medium, Appl. Microbiol. Biotechnol. 64 (5) (2004) 686-690.

[42] A. Schmid, B. Sonnleitner, B. Witholt, Medium chain length alkane solventcell transfer rates in two-liquid phase, Pseudomonas oleovorans cultures, Biotechnol. Bioeng. 60 (1) (1998) 10-23.

[43] C. Laane, S. Boeren, K. Vos, C. Veeger, Rules for optimization of biocatalysis in organic-solvents, Biotechnol. Bioeng. 30 (1) (1987) 81-87.

[44] A.A. Chakraborty, R.P. Phadke, F.A. Chaudhary, P.S. Shete, B.S. Rao, K.D. Jasani, Optimization of redox reactions employing whole cell biocatalysis, World J. Microbiol. Biotechnol. 21 (3) (2005) 221-227.

[45] L.E. Husken, J. Hoogakker, J.A.M. de Bont, J. Tramper, H.H. Beeftink, Model description of bacterial 3-methylcatechol production in one- and two-phase systems, Bioprocess Biosyst. Eng. 26 (1) (2003) 11-17.

[46] L.E. Husken, M. Oomes, K. Schroen, J. Tramper, J.A.M. de Bont, R. Beeftink, Membrane-facilitated bioproduction of 3-methylcatechol in an octanol/water two-phase system, J. Biotechnol. 96 (3) (2002) 281-289.

[47] R.D. Schwartz, C.J. Mccoy, Epoxidation of 1,7-octadiene by Pseudomonas oleovorans-fermentation in presence of cyclohexane, Appl. Environ. Microbiol. 34 (1) (1977) 47-49.

[48] F. Grivel, C. Larroche, Phase transfer and biocatalyst behaviour during biotransformation of beta-ionone in a two-phase liquid system by immobilised Aspergillus niger, Biochem. Eng. J. 7 (1) (2001) 27-34

[49] F.C. Ferreira, L. Peeva, A. Boam, S.F. Zhang, A. Livingston, Pilot scale application of the membrane aromatic recovery system (MARS) for recov- 
ery of phenol from resin production condensates, J. Membr. Sci. 257 (1/2) (2005) 120-133.

[50] L. Giorno, J.C. Zhang, E. Drioli, Study of mass transfer performance of naproxen acid and ester through a multiphase enzyme-loaded membrane system, J. Membr. Sci. 276 (1/2) (2006) 59-67.

[51] F.X. Pierre, I. Souchon, M. Marin, Recovery of sulfur aroma compounds using membrane-based solvent extraction, J. Membr. Sci. 187 (1/2) (2001) 239-253.

[52] R. Prasad, K.K. Sirkar, Hollow fiber solvent-extraction-performances and design, J. Membr. Sci. 50 (2) (1990) 153-175.

[53] A.G. Livingston, J.P. Arcangeli, A.T. Boam, S.F. Zhang, M. Marangon, L.M.F. dos Santos, Extractive membrane bioreactors for detoxification of chemical industry wastes: process development, J. Membr. Sci. 151 (1) (1998) 29-44.
[54] L.F. Strachan, A.G. Livingston, The effect of membrane module configuration on extraction efficiency in an extractive membrane bioreactor, $\mathrm{J}$. Membr. Sci. 128 (2) (1997) 231-242.

[55] D.A. Fletcher, R.F. McMeeking, D. Parkin, The United Kingdom chemical database service, J. Chem. Inform. Comput. Sci. 36 (4) (1996) 746-749.

[56] A. King, J.R. Dickinson, Biotransformation of monoterpene alcohols by Saccharomyces cerevisiae, Torulaspora delbrueckii and Kluyveromyces lactis, Yeast 16 (6) (2000) 499-506.

[57] E. Vaudano, E.G. Moruno, R. Di Stefano, Modulation of geraniol metabolism during alcohol fermentation, J. Inst. Brewing 110 (3) (2004) 213-219.

[58] M. Bard, M.R. Albrecht, N. Gupta, C.J. Guynn, W. Stillwell, Geraniol interferes with membrane functions in strains of Candida and Saccharomyces, Lipids 23 (6) (1988) 534-538. 